\title{
Santuarios, oráculos, montañas y orden sagrado en la cordillera del Vilcabamba-Cusco ${ }^{1}$
}

\author{
Sanctuaries, oracles, mountains and sacred order in the Vilcabamba- \\ Cusco mountain range
}

\author{
Wilber Bolívar Yapura \\ https://orcid.org/0000-0003-2089-4411 \\ Universidad Nacional de San Antonio Abad del Cusco \\ wilberbolivar@gmail.com
}

\section{RESUMEN}

Este trabajo se construye sobre la base de exploraciones arqueológicas en la cordillera del Vilcabamba, depositaria de una vastedad en restos arqueológicos, que corresponden a diversos periodos y fases de ocupación humana, nuestro objetivo fueron las montañas sagradas en su rol como deidades, guardianes protectores y oráculos; en colaboración con sacerdotes andinos, logramos percibir que tienen un orden sagrado y jerarquizado, son una cofradía con un territorio, ellos conversan tomando decisiones para el clima de la región. Sus súbditos piden permiso con ofrendas para transitar por su territorio, realizar sus actividades, así como ser protegidos. Las cualidades que posee el área se enmarcan en sus características geográficas con arquitectura peculiar, adaptadas a la geografía sagrada, asociado a un manejo territorial de volúmenes y soluciones a la difícil topografía, además de la conducción de espacios dentro de la concepción del paisaje en la ideología Inka.

1. En homenaje a una gran colega y amiga Gladys Lagos Aedo, que se encuentra en el Hanaxpacha. 
Palabras clave: Hatun Vilcabamba, montañas, oráculos, orden sagrado, paisaje, parentela y santuarios

\section{ABSTRACT}

This work is built on the basis of archaeological explorations in the Vilcabamba mountain range, depository of a vast amount of archaeological remains, which correspond to various periods and phases of human occupation, our objective was the sacred mountains in their role as deities, protective guardians and oracles; In collaboration with Andean priests, we were able to perceive that they have a sacred and hierarchical order, they are a brotherhood with a territory, they talk making decisions for the climate of the region. His subjects ask permission with offerings to travel through their territory, carry out their activities, as well as be protected. The qualities that the area possesses are framed in its geographical characteristics with peculiar architecture, adapted to the sacred geography, associated with a territorial management of volumes and solutions to the difficult topography, in addition to the conduction of spaces within the conception of the landscape in the Inka ideology.

Keyworks: Hatun Vilcabamba, mountains, oracles, sacred order, landscape, kindred and sanctuaries.

Recibido: 13/08/2021 - Aceptado: 21/09/2021 - Publicado: 25/11/2021

\section{INTRODUCCIÓN}

Iniciamos a través de un enfoque conceptual de corte cualitativo abordando la metodología que propone la arqueología del paisaje, para contextualizar las montañas sagradas enclavadas en la cordillera del Vilcabamba, las hemos coligados con los caminos que sirvieron para transitar, transportar productos y los que se dirigen a los adoratorios. No cabe duda que los santuarios y enclaves religiosos, tuvieron un rol fundamental como espacios de adoración a las montañas convertidas en deidades andinas. A pesar de que existen muchísimos santuarios dispersos en toda esta área, solo nos da tiempo en esta oportunidad de abordar dos de ellos, el primero como espacio corporal-edificado de Choqhechurko y Yanaorqo, ultimo santuario inka para el Choquezafra.

Los sacerdotes andinos fueron y son los interlocutores entre montañas y pobladores, quienes primero piden permiso y solicitan autorizaciones para caminar, pastar ganados, cultivar sus chacras y otras actividades afines, estos tienen el don de escuchar e interpretar las conversaciones que tienen las montañas, además perciben la parentela y orden sagrado de las montañas, que a su vez, no solo fueron protectores, oráculos y dadores de vida, también desempeñaron un papel de primer orden en la planificación y ordenamiento territorial en Vilcabamba. Finalmente, hacemos una 
descripción en orden jerárquico de los Apus, principales como el Salkantay, Padreyoq, el Macizo del Panta, Pumasillo, Azulrithy (Azulcocha), Choquezafra y Chontawilca, a pesar de figurar otras montañas de segundo orden como el Chacrantica, Palkay. Finalmente proponemos un acercamiento sobre la base de nuestro trabajo.

\section{Enfoque conceptual}

Abordamos desde un enfoque cualitativo, observando los elementos en su medio natural para luego examinarlos, atendiendo a su temporalidad, la recolección de datos correspondió varios momentos de carácter descriptivo. Para esto consideramos el principio básico de la arqueología del paisaje, en la cual las sociedades del pasado no se limitaban a vivir, deshacerse de artefactos a construir vías de comunicación, asentamientos, sino que interactuaron con el paisaje (Jhonson 2008, p. 72).

Abordamos la construcción de infraestructura religiosa en el paisaje en términos económicos, que nos conlleva a examinar el territorio a través de las modificaciones (construcciones de Santuarios y enclaves) como expresión de un sistema de significados culturales, incluidas las montañas y su sacralidad, de tal forma que el ser humano interpreta el mundo y actúa sobre él, en sintonía con el paulatino énfasis en las perspectivas cognitivas. Por ejemplo, el territorio que incluye caminos prehispánicos, sitios arqueológicos en el área de la cordillera del Vilcabamba, nos acarrea a interpretar y vincular las diferentes zonas ecológicas, a través de las relaciones económicas complementarias, puesto que dentro de la ideología Inka, se ligó los caminos y las montañas a las divisiones conceptuales del espacio y la sociedad, estos fueron una forma de concebir y expresar la geografía cultural encadenada al paisaje. Muchos de estos caminos siguen intactos en su trazo y concepciones mágicas ideológicas y escondidas en la espesura del bosque, consideramos contextualizando los sitios de Choquechurko como santuarios de adoración al Salkantay y Humantay, luego el recientemente ubicado Yanaorqo por Bolívar (2002) en advocación de la montaña de Choquezafra.

\section{METODOLOGÍA}

Bunge (1981) sostiene "donde no hay método científico no hay ciencia" citado además por Jiménez y Tejada (2004), entonces podemos determinar, que la investigación científica es la acción de aplicar el método científico; señalando que entre investigación científica y conocimiento científico está el método científico, concibiendo por método científico la forma mediante el cual obtenemos el conocimiento de la realidad. Para la Arqueología del Paisaje, la metodología es el procedimiento que permite ajustar la certidumbre del nuevo conocimiento, esta metodología a sido usada en el presente trabajo, usualmente el análisis antropológico estructural, "se basa en comparar modelos formales de organización del espacio desprendidos del estudio de diferentes códigos arqueológicos" (Criado Boado, 1999, p. 17). 
Este método está esquematizado en etapas secuenciadas, con comparaciones y analógias cuyas herramientas metodológicas consisten en: análisis formal, etapa deconstructiva, etapa descriptiva y etapa interpretativa.

La metodología es un procedimiento que nos permite obtener nuevo conocimiento que debe estar previstos para cada investigación que se realice. En la Arqueología del Paisaje "la metodología implica describir los principales instrumentos que nos permiten estudiar las dimensiones y aspectos temáticos que conforman los paisajes arqueológicos" (Criado Boado, 1999, p. 17).

\section{LAS MONTAÑAS SAGRADAS Y LA CORDILLERA DEL VILCABAMBA}

Emplazada hacia el Sur del Perú ocupando aproximadamente $260 \mathrm{~km}$, es pequeña en comparación a la cordillera de los Andes. Esta cadena muestra erosiones ocasionados por los ríos, con cañones recónditos cuyas montañas tienen como el Salkantay (6271), Padreyoq (5771), Coriwayrachina (5365), Pumasillo (5918), Panta (5840), Azulrithy-Azulqocha (5259), Choquezafra (5184) y Chontawilca (4586). Según Bolívar manifiesta que la menos reconocida de estas es el "Pumasillo (garra del puma) con 5918 m.s.n.m., que no es una montaña solitaria, sino agrupado a otros de mayor jerarquía. El Pumasillo no está visible para las comunidades de su entorno, sin embargo, su presencia es registrada en mapas desde el año 1956" (Bolívar 2016: 143). Por otro lado, Apaza y Bolívar (2016) manifiestan que la cadena montañosa del Vilcabamba alberga a los otros Cusco.

“...es importante establecer que los otros Cusco, no son una copia espacial o arquitectónica del Cusco principal, más bien es una construcción bajo el concepto Cusco, armonizándose con la geomorfología y medio ambiente de la zona, lo que implica que la modificación (construcción) de su espacio, mental o geográfico se sustenta en que estos estaban entendidos bajo los criterios de lo que significaba este Otro Cusco, núcleo del sistema de organización y manejo de este espacio territorial, esto se repetiría de la misma manera en todo el Tawantinsuyo" (Apaza y Bolívar, 2016, p. 192).

Están los sitios de Machu Picchu y Choquequirao en primer orden, luego le siguen los enclaves de Rosaspata, Ñustahispana, Espiritupampa y Hatun Vilcabamba (Vilcabamba la grande) último refugio sagrado y Cusco inka.

Esta cadena de montañas es complicada porque con sus aguas que emanan de sus cimas nutre los nacientes riachuelos que forman ríos, que, a su vez son tributarios del Vilcanota, Urubamba, bajo Urubamba en el Cusco y al Apurímac en esa jurisdicción. Los principales picos con una altura de cinco mil metros son cinco, consignados en documentos del siglo XVI, cuando anotan los enfrentamientos iniciados por Manco Inca contra los españoles. 
Estas montañas atestiguaron miles de años atrás según Bolívar (2016) una continuidad de ocupación temporal, culminando en establecimientos de poblaciones que ocuparon espaciosas áreas de la cordillera del Vilcabamba. Las actividades agrícolas, de pastoreo, mineras y fabricación de cerámica, alimentaron una dinámica actividad comercial que vinculo la variedad productiva en los diversos ambientes, cita a Murra (1975) quien sostiene “...se dio una inducción en la complementariedad y control vertical de un máximo de pisos ecológicos en la economía de las poblaciones andinas con agroecosistemas adaptados a las montañas así como la puna, los valles interandinos, las selvas lluviosas del piedemonte, las sábanas y los bosques litorales". Bolívar (2015) por su parte manifiesta que esta clasificación y los saberes surgidos de las experiencias usadas para aplicar y gestionar los ambientes de montaña, han sido alteradas por la nueva categorización y conducción aplicada por los occidentales, quienes requirieron varios siglos para establecerse en gran parte de este territorio, sometiendo a sus poblaciones bajo estrictas órdenes destruyendo y transformando su medio ambiente, así como sus modos de vida.

Carlotto y otros, refieren:

“...que la Cordillera de Vilcabamba ocupa la zona Suroeste en la provincia de la Convención. Limita con el río Apurímac en el Suroeste, desarrollando una pendiente escabrosa, mientras que en el Norte el paso es escalonado con dirección a la pendiente Norte en la Cordillera Oriental. Esta unidad geológica también comprende la provincia de Urubamba" (Carlotto et, al 1999, p. 11)

\section{Caminos a los adoratorios de montañas sagradas}

Probablemente ya existían desde el Horizonte Medio, utilizados por los Tiahuanaco para su incursión en territorio ayacuchano y luego por los Wari, para consolidar su presencia en área cusqueña, estos fueron construidos para el traslado de diferentes productos regionales con alto grado de inversión energética, estos caminos a su vez pasaron por inmediaciones de nevados como el Salkantay y Humantay en Mollepata, luego al Choquezafra en Vilcabamba, también con fines religiosos a los santuarios. Existen otros caminos aun no identificados plenamente de los cuales se tiene algunos tramos, en nuestra travesía por Hatun Vilcabamba, ubicamos algunos de estos, el que nos interesa es el que se dirige del santuario de Yanaorqo construido para rendir culto al Choquezafra, Apu tutelar, protector y oráculo de esta área además de ser el último Cusco refugio sagrado de los inka en Vilcabamba.

Bolívar y otros (2019) manifiestan que:

"En consecuencia, la red vial que articuló estos espacios atravesaba por un medio físico variado, pues se hallan alineamientos montañosos, quebradas profundas y centros arqueológicos administrativos en Vilcabamba, los que 


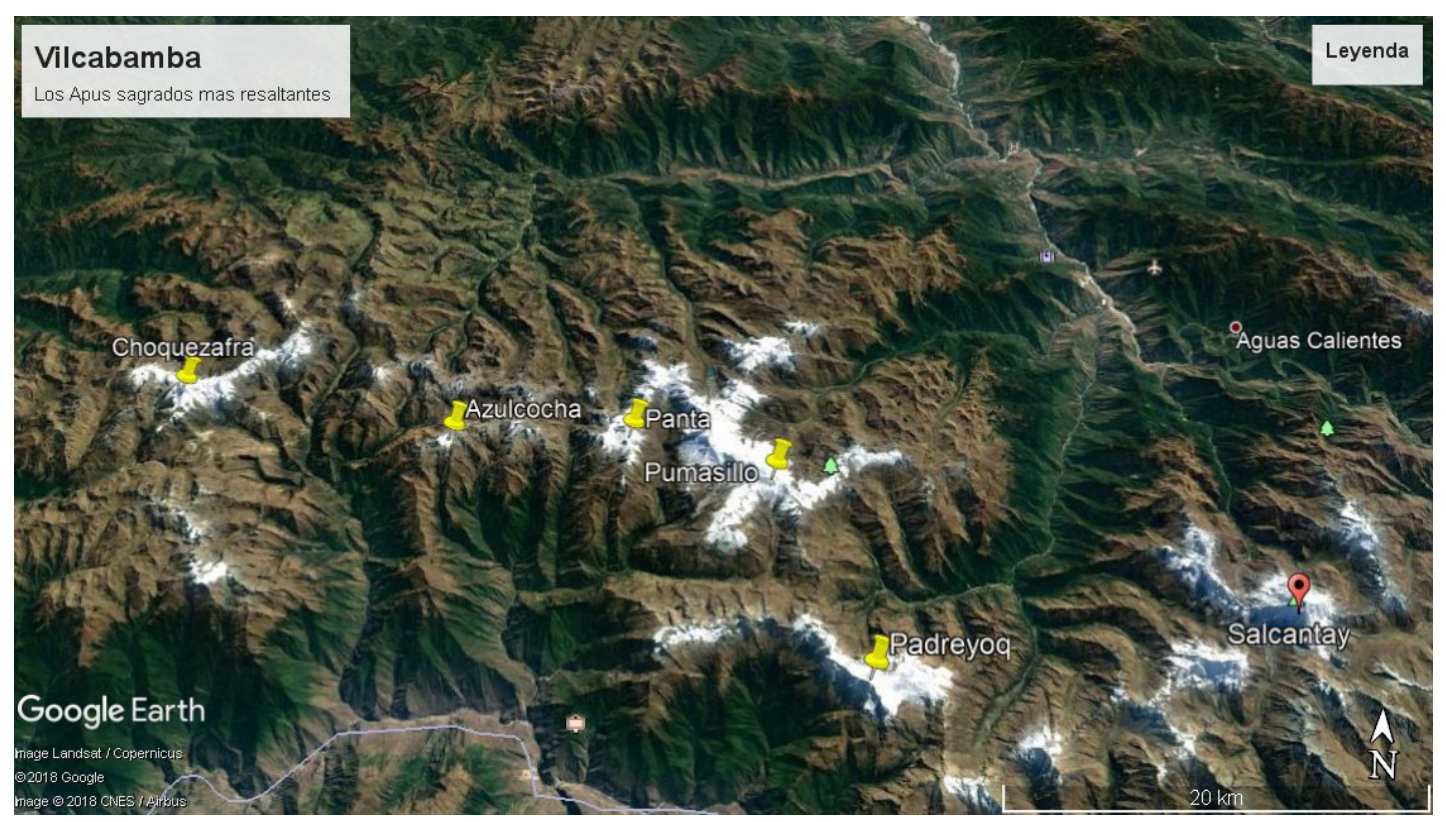

Figura 1. Escenario de montañas sagradas en el macizo de la cordillera del Vilcabamba. Fuente Google Earth (2018).

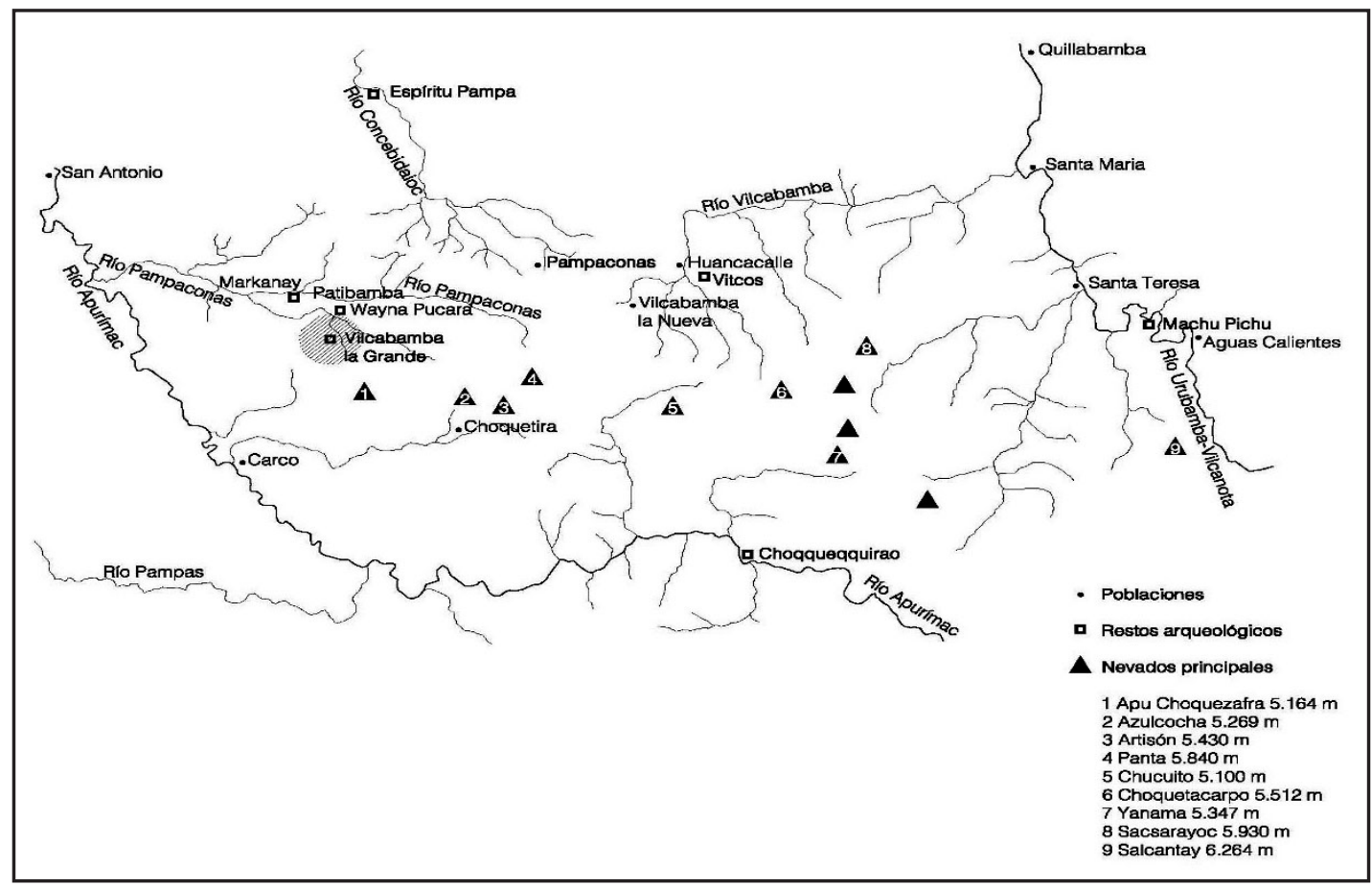

Figura 2. Ubicación de los nevados principales en la cordillera del Vilcabamba. Tomado de Vilcabamba. El refugio Sagrado de los Incas. Santiago del Valle (2016) 
fueron organizados estructuralmente de manera apropiada y estratégica para albergar a una población que estaba socialmente estratificada, es decir, estaba representada por una clase social alta que correspondía al Inka y su panaca real que, junto a los sacerdotes, se encargaban de la administración de estos centros y de todo el valle de Vilcabamba. En este sentido la presencia de caminos fue fundamental para el desarrollo y la comunicación entre las zonas templadas y Suni" (Bolívar y otros 2019: 93)

Estos acontecimientos nos conducen a reconocer que estas vías contienen representaciones simbólicas, así como interconexión regional, con diferentes abordajes, comprendiendo a estas como los caminos ceremoniales a las montañas objeto de culto ancestrales, guardianes y oráculos. Los pobladores andinos desde siempre trasformaron los paisajes simbólicamente, otorgándole vida y contenido a través de su componente natural, representado por elementos que los rodean, además construyeron una estructura de sobrenombres y cuentos de lugares cuya narración actúa sobres sus actitudes frente a las montañas su paisaje y los caminos.

De nuevo Bolívar et. al. sobre estos caminos sostienen:

"La traza y características de estos tramos de los caminos son impresionantes, por su planificación única y singular, que está acondicionada a las particularidades de la geografía del terreno. Las plataformas artificiales están cuidadosamente adaptadas a la topografía sobre la que se construyeron las infraestructuras de los caminos, tambos, chasquiwasis, apachetas y otros que forman parte del camino. Algunas características se perciben en los centros administrativos de Choquechurko, Vitkus, Choquequirao, Espiritupampa y Machupicchu, que están asociados a los caminos que, probablemente, fueron sitios ceremoniales de naturaleza religiosa". (Bolívar et, al 2019, p. 94)

Por otro lado, Soto (2016) infiere lo siguiente:

"Los detalles arquitectónicos de los caminos prehispánicos son muy importantes, sobresaliendo las técnicas constructivas de los muros de contención y retención del camino, mostrándose en las diferentes secciones las evidencias de tipologías de caminos, tales como despejado/sendero, plataforma con corte talud, plataforma con empedrado y muro de sostenimiento de terraplén, plataforma con corte talud sin muro de sostenimiento, plataforma de tierra con muro de sostenimiento de terraplén, excavado en zanja encerrado con muros laterales, escalinatas y plataforma con muro de sostenimiento de terraplén, tallado en roca, escalinatas talladas en roca, etc. chasquiwasis, apachetas y otros que forman parte del camino". (Soto, 2016). 


\section{Santuarios y enclaves religiosos}

Las montañas han desempeñado un rol fundamental en la vida cotidiana de los pobladores andinos desde épocas tempranas, sin embargo parece que desde el Intermedio Tardío, de dio énfasis en la construcción de santuarios o enclaves, donde se realizaba culto a estos, en la codillera del Vilcabamba, una de las montañas sagradas que se posesiona dentro del orden jerárquico como principal y mayor es el Salkantay, flanqueada por los nevados del Umantay y Yanantay, que vendrían a ser sus hijos, una de estas construcciones religiosas y administrativas es el sitio de Choqhechurko y el otro Yanaorqo, nuevos para la literatura arqueológica.

\section{El espacio corporal y edificado de Choqhechurko}

Halla por los años 2005, tuve la oportunidad de llegar por primera vez a este sitio, del que elaboré un informe técnico de campo para iniciar las gestiones en su intervención arqueológica. La Dirección Regional de Cultura (2014) interviene en el sitio encarga a la arqueóloga Jhosselim Ortiz de Orue. Este se ubica geopolíticamente en Cusco, prov. De Anta distrito de Anta y CC. de Marcahuaylla. Se toma la vía principal Cusco - Abancay, hasta Mollepata, de este punto sale un ramal que se bifurca en el sitio de Cruz Pata, desde donde se visualiza el cerro (Choqhechurqo). Se prosigue por un sendero que asciende hacia el noreste de la quebrada del cerro, a $2 \mathrm{Km}$. tras una caminata sed llega al santuario de Choqhechurko.

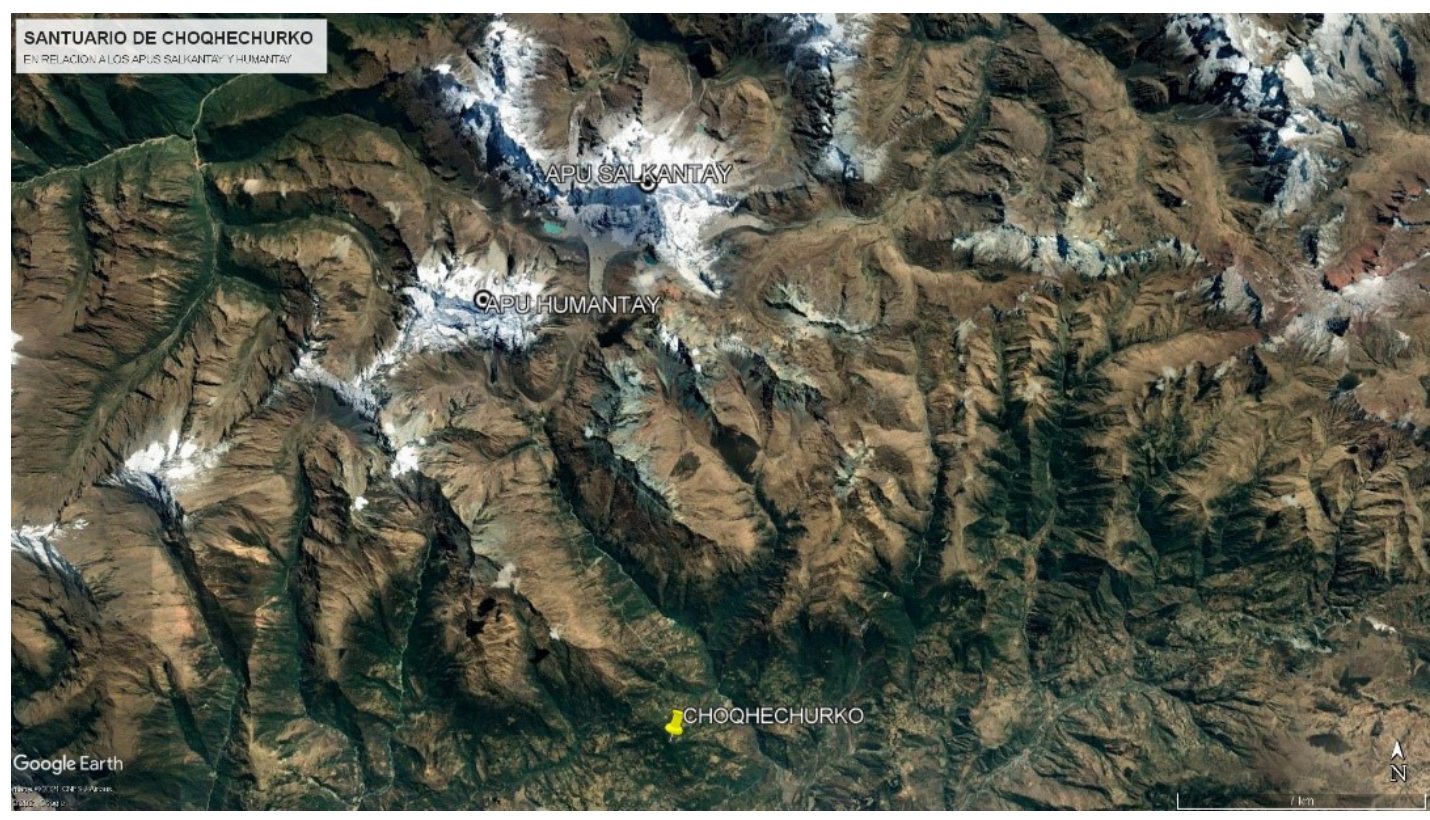

Figura 3. Véase el enclave de Choquechurko en relación las montañas sagradas del Salkantay y Humantay. Fuente Google Earth (2021). 


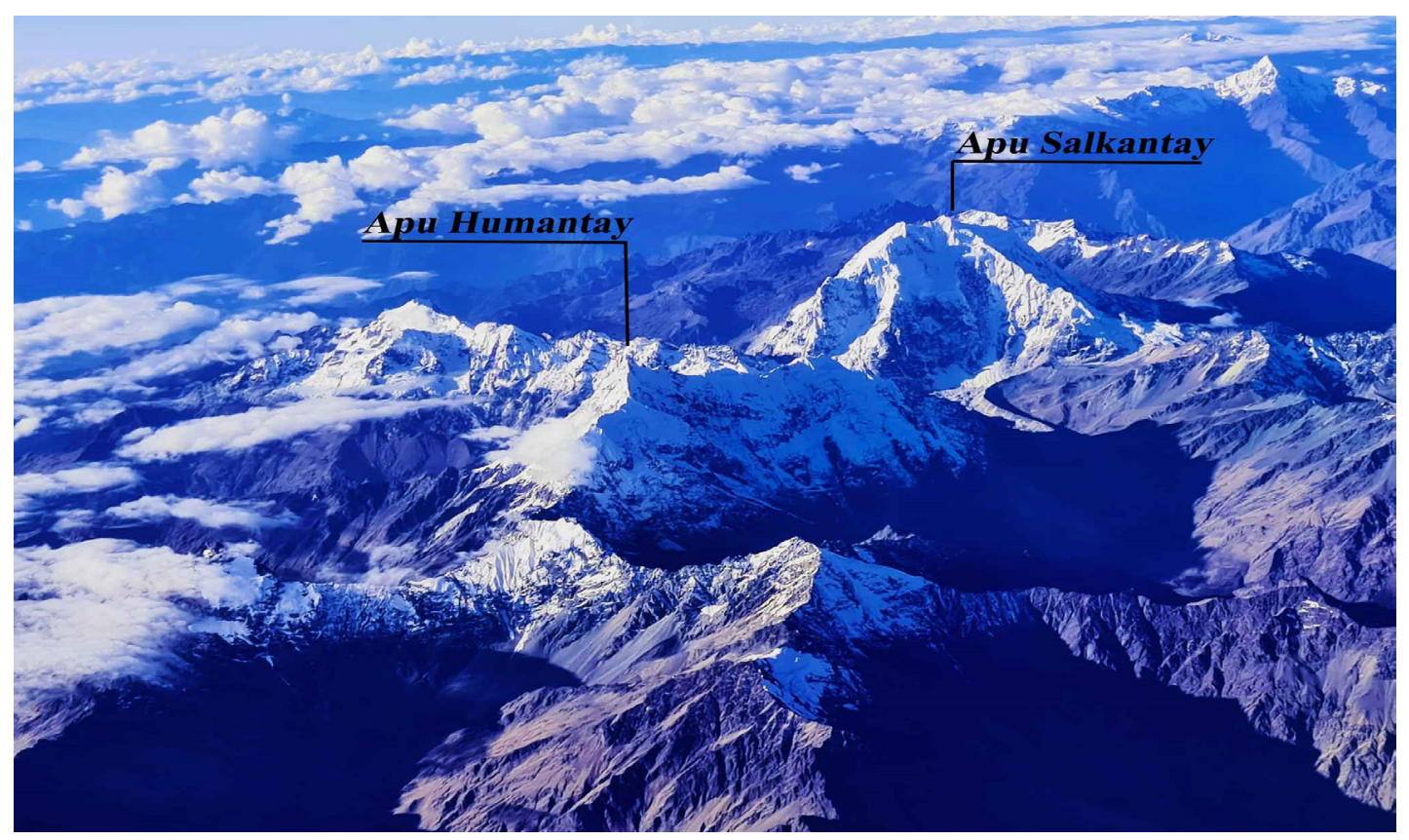

Figura 4. Foto aérea de la cordillera del Vilcabamba con los Apus Salkantay y Humantay. Tomada de Facebook 12/07/2021 (Jorge Luis Delgado M.)

Su ubicación es estratégica por estar emplazada encima de afloramientos rocosos de caliza pertenecientes a la Formación geológica Maras, rodeada de vegetación arbustiva y arbórea de la zona, predominando arboles de chachacomo (Escallonia resinosa). En la red hídrica aledaña este sitio, está el río Blanco ubicado al lado este, originado por los deshielos de los nevados Salkantay y Humantay, considerados desde época prehispánica como apus tutelares de la zona, específicamente el Salkantay fue uno de los apus principales en época inka. Este emplazamiento presenta una relación estrecha con estos nevados, ya que de acuerdo a los estudios realizados por el Proyecto Qhapac Ñan (2010) se determinó que la vía que parte del poblado de Mollepata con destino al Salkantay, conecta el santuario de Choqhechurko, siendo esta ruta importante para acceder a tierras del Antisuyo en especial hacia Vilcabamba, Santa Teresa, Machupichhu, Choquekirao entro otros.

Es evidente la interacción entre espacio físico y construido manifestado en las estructuras arquitectónicas, cuya disposición y planimetría se relacionan con las configuraciones fisiográficas, revelando la estrecha dependencia y vínculo entre la persona y el medio geográfico.

Desde tiempos prehispánicos siempre se consideró a las montañas como entes vivientes a quienes se les respetaba porque formaban parte de su vida cotidiana; las permutas de las sociedades pueden ser observados a través de la investigación ar- 
queológica, expresados en las siguientes dimensiones del paisaje: espacios material, social y imaginado, llegando a entenderse los códigos humanos en sociedad para observar de mejor manera el paisaje.

La construcción de este sitio y su planificación estaba predispuesto y orientado hacia el norte, donde se ubican los nevados Salkantay y Humantay. La visualización de Choqhechurko y el espacio físico circundante hace inferir que este fue un espacio administrativo de control y enclave religioso, expresado en los diferentes componentes del área construida. Estas evidencias contienen construcciones como: muros curvos, plataformas o ushnu, vanos o puertas de acceso, "tianas", asientos y nichos trapezoidales los cuales se homologan con la ideología.

Los nichos trapezoidales de aparejo fino, el símbolo escalonado labrado en roca y las estructuras arquitectónicas al interior de una cueva, se asumen como contenido simbólico de estatus social, especialmente las representaciones escalonadas y ascendentes le asignan un sentido de rango por encima de otros elementos constructivos. Lo repetitivo de líneas y símbolos escalonados presentes en casi todos los espacios, así como nichos trapezoidales ventanas, jambas y los ambientes de cada patio la hacen un área especial

Definitivamente está ligado al poder de las montañas, a sus roles de oráculos la observación del medio ambiente, eventos de intensas lluvias acompañadas de truenos, que fueron traducidos por los sacerdotes como comunicaciones a sus súbditos,

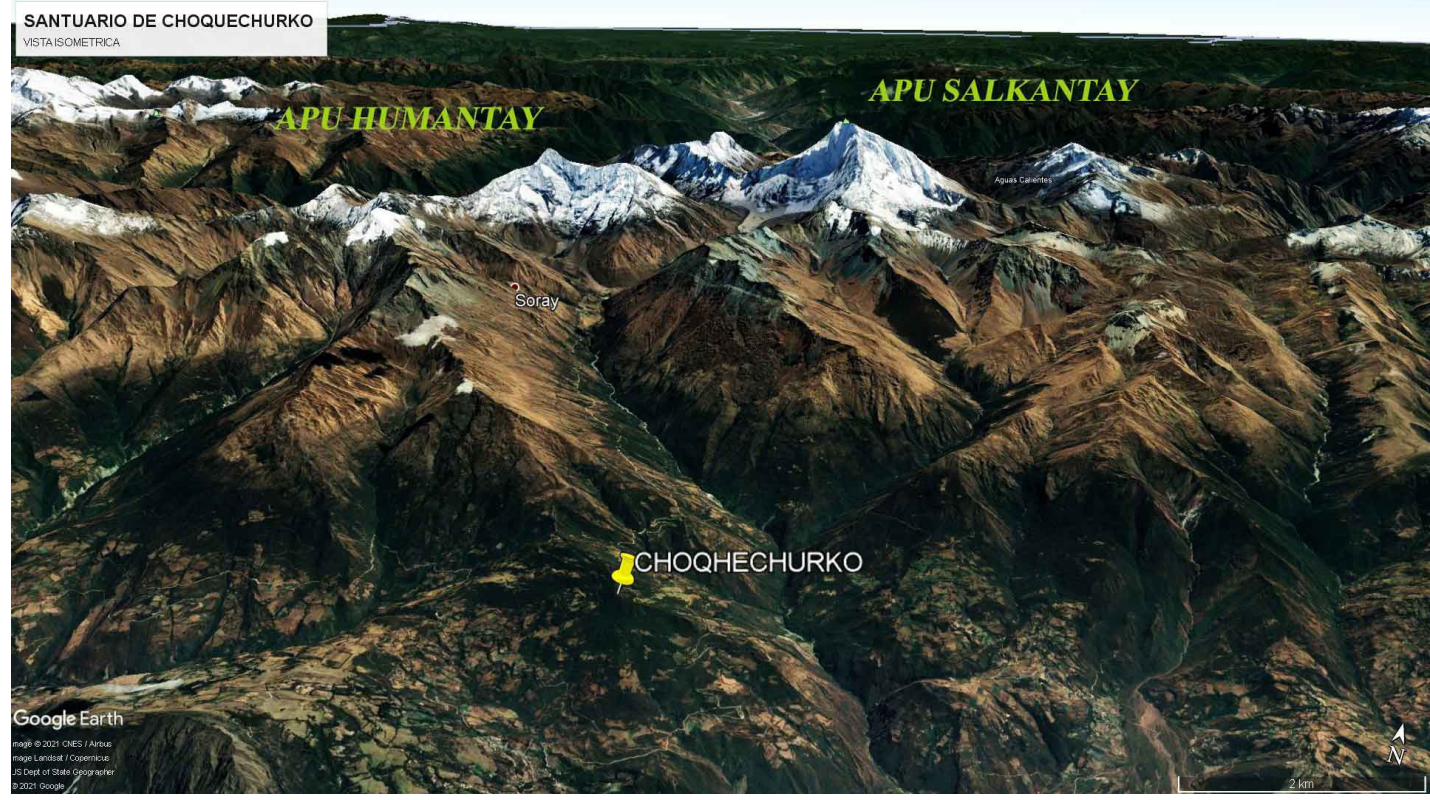

Figura 5. Isometría del Santuario de Choqhechurko en relación a los Apus Salkantay y Humantay Fuente: Google Earth (2021). 
estas características indicarían que el patrón de racionalidad de espacios privados inka no es ajeno a Choqhechurko, presumiendo estuvo habitado por la élite sacerdotal procedente del axis mundi Cusco. Pese a que hay sectores donde la topografía determinaba el tipo de estructura arquitectónica, esta construcción estaba regulada por la religión y las actividades que en esta se desarrollarían.

Es evidente que la simbiosis entre el espacio físico y simbólico se materializaban en su arquitectura, de este modo las expresiones sociales acontecidas quedaban intrínsecamente unidas con la disposición visual hacia los nevados Salkantay y Humantay, este último también considerado apu tutelar, al mismo tiempo sería un hito de ubicación referencial. Los espacios, edificado y físico además de manifestar una atadura visual exhiben otras relaciones tales como la interrelación física, social y cultural, en la que el medio ambiente y el espacio físico generan un lazo indispensable para asumir la plasmación de la sacralidad inka de manera majestuosa e histórica. Esta interacción también se ve plasmada con las evidencias registradas de fragmentos de cerámica tanto de afiliación cultural inka, como contemporánea.

En cuanto a los factores organizativos y de planificación Choqhechurko, presenta nexos con poder simbólico del lugar, su orientación, sus vistas y accesos, así como la organización de estructuras entorno al espacio físico y su arquitectura se encuentra "interrelacionados en función de su proximidad a las montañas sagradas, el cual permite asumir relaciones espaciales contiguos, identificados por medio de corredizos, áreas abiertas y afloramientos rocosos a manera de hitos de distribución y separación de sectores; la ordenación espacial sería el de Organizaciones radiales, concentrando por los afloramientos rocosos ocupando espacios centrales dominantes.

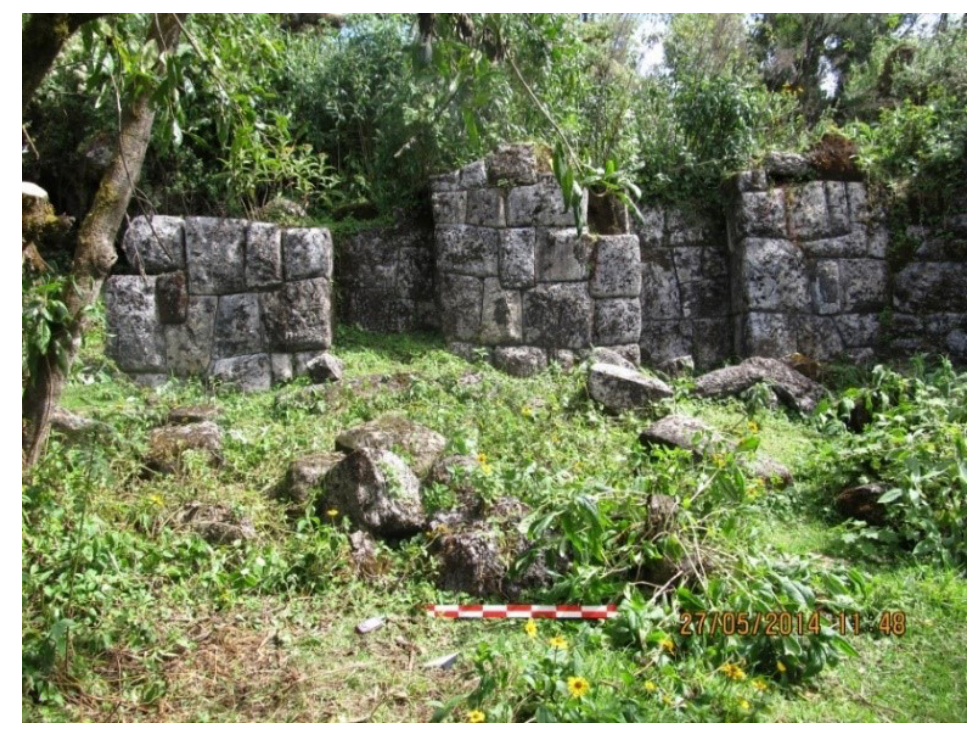

Figura 6. Nichos trapezoidales. Foto. Ortiz de Orue (2014). 


\section{Yanaorqo, último Cusco y santuario inka para el Choquezafra}

Para rendirle culto al Choquezafra, se construyeron otros enclaves uno de ellos excavado por Bolívar, (2002) quien nos manifiesta lo siguiente:

"El sitio de Yanaorqo es el más importante de toda el área explorada, por su ubicación estratégica y la presencia de las estructuras Inkas. La edificación está asociada a un espacio sagrado en la cima de una colina delimitada por muros a manera de una muralla que rodea la cima de la montaña. Desde este espacio se puede dominar generosamente los valles de Pintobamba, Chancavine, Toroq los cerros de Senqa Loma, Koriwayrachian y otros más.

En estos espacios contiguos hallamos la presencia de cerámica Inka (dos cuellos), los otros fragmentos son del tipo domestico local, los cuales se hallaron en un basural ubicado en la esquina Noroeste, al consumar la limpieza de la maleza y los árboles que rodeaban el ambiente Inka de Yanaorqo.

Por lo espeso de la vegetación la estructura Inka está muy estropeada, inclusive colapsó por uno de sus lados por donde está un vano de acceso. Este recinto tiene 10 hornacinas, una piedra de batan en una esquina el cual presenta un desgaste moderado

El recinto Inka, tiene un espacio de regulares dimensiones a su entorno que está rodeado por muros de contención y la muralla que encierra la cima del cerro, junto a este recinto en el lado Sur se aprecia una gran roca sobre el piso que debió tener funciones ceremoniales.

A media cuesta hacia abajo se tiene otro recinto de forma irregular casi elíptica, la cual ha sido construida aprovechando la topografía del terreno, esta también es delimitada por un muro perimétrico (R-2) del recinto solo se puede apreciar las piedras de la cimentación, con un acceso muy sencillo el cual está delimitado por dos lajas de regulares dimensiones en cada costado y unos maranes que servían para moler granos, tanto en el interior como el exterior del recinto, el maran de la parte exterior es la que tiene mayor desgaste por el uso a que ha sido sometido.

Hacia el norte de Yanaorqo se Identificó otro sitio ,hasta la fecha no identificado, llamado por nosotros Cochayoq Wasi, en un lugar muy singular, el espacio utilizado es un abrigo rocoso, está dispuesto al costado de un estanque o Cocha el cual está seco y lleno de vegetación que impide definir el área que está ocupada aunque el ambiente o Machay es pequeño solo se aprecia parte de las piedras utilizadas en la cimentación, con material del sitio, dispuestos en una sola hilada como límite de espacio habitacional, el cual bien podría ser vivienda temporal de pobladores de grupos étnicos locales" (Bolívar 2002). 

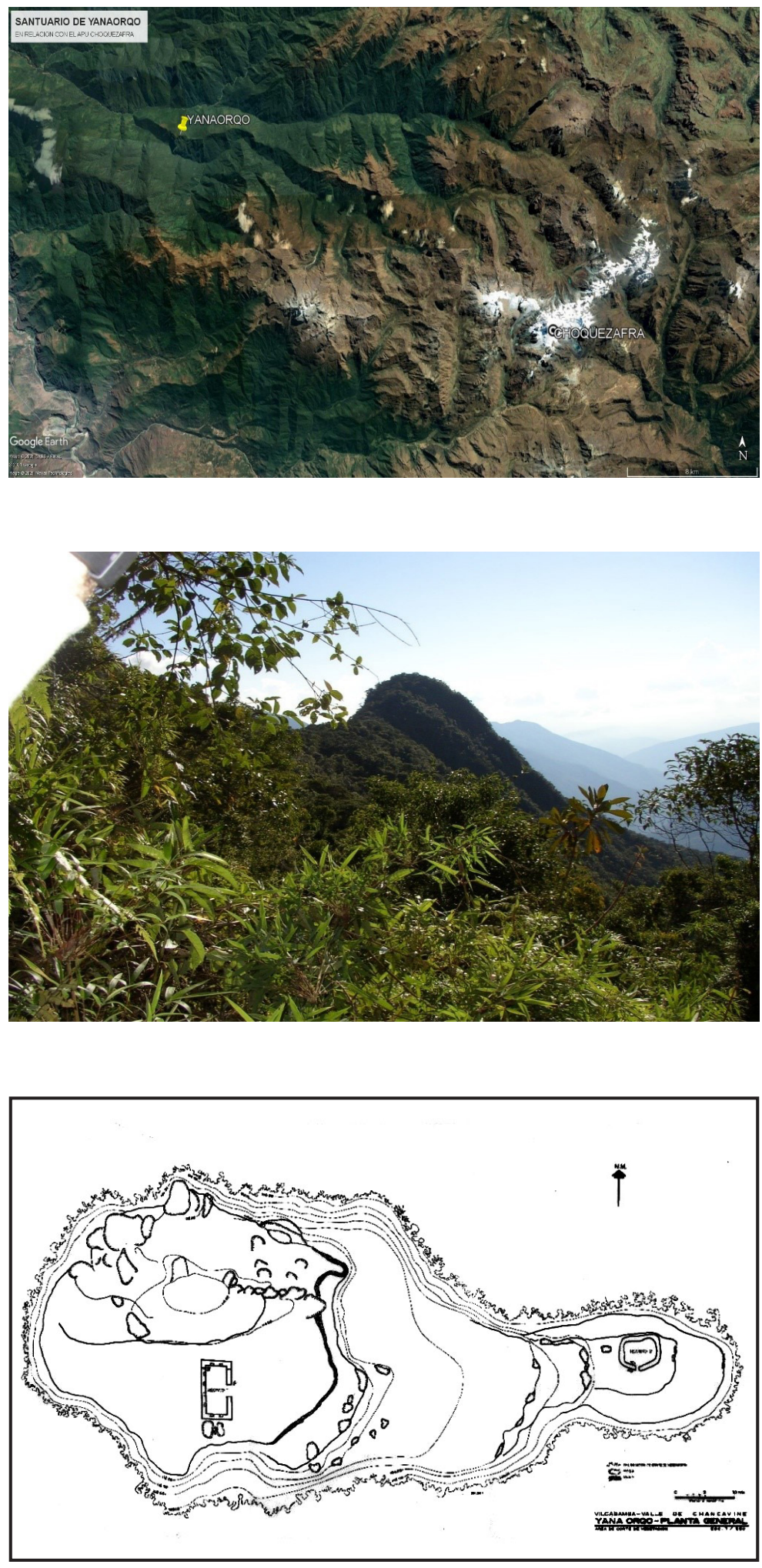

Figura 9. Yanaorqo (cerro negro) el último santuario inka en Vilcabamba. Fuente Google earth (2021).

Figura 10. El santuario oculto en la cima de Yanaorqo, visto desde la espesura del monte antes de su intervención.

Figura 11. Plano de Planta general con 02 recintos ubicados en la cima de Yanaorqo, el primero dedicado al culto $y$ el segundo como estructura auxiliar. Dibujo Zapata (2002). 

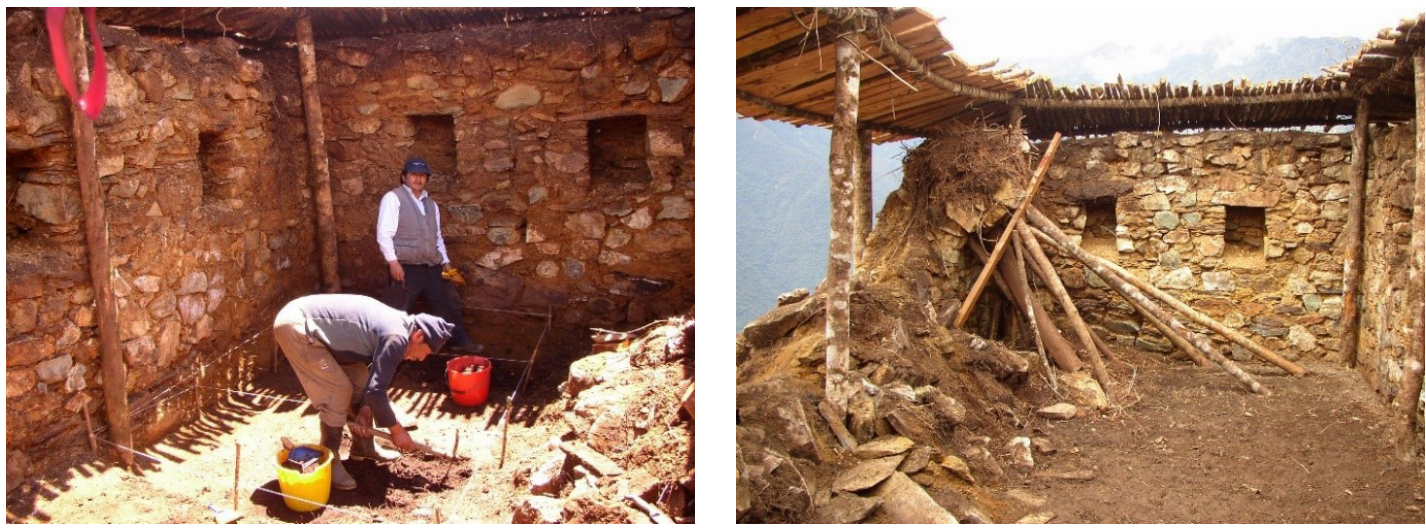

Figura 12. Proceso de excavación y medidas de mitigación para la conservación del santuario (2002).

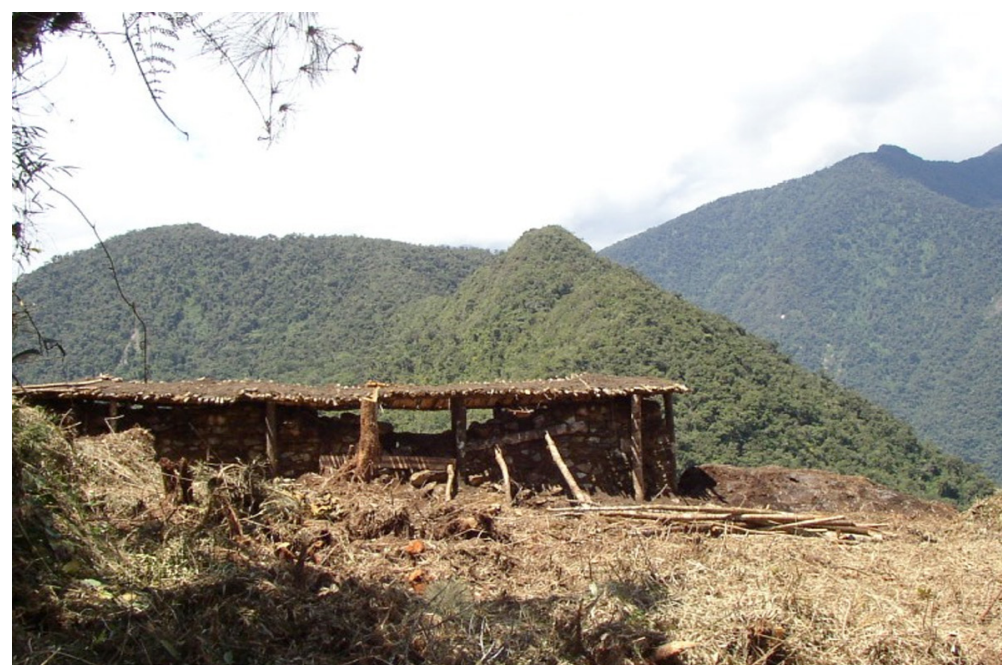

Figura 13. Recinto de culto en la cima de Yanaorqo, liberado de la espesura del bosque tropical dedicado al Choquezafra Foto Santiago del Valle (2002).

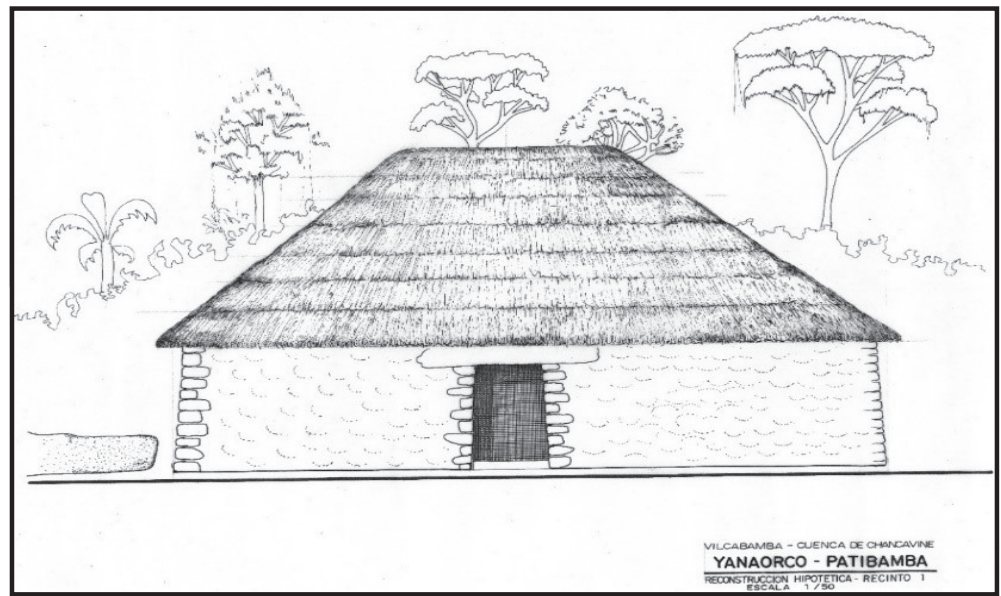

Figura 14. Propuesta reconstrucción hipotética recinto ceremonial Inka, con revoque de arcilla $y$ pintado. Dibujo Zapata (2002). 


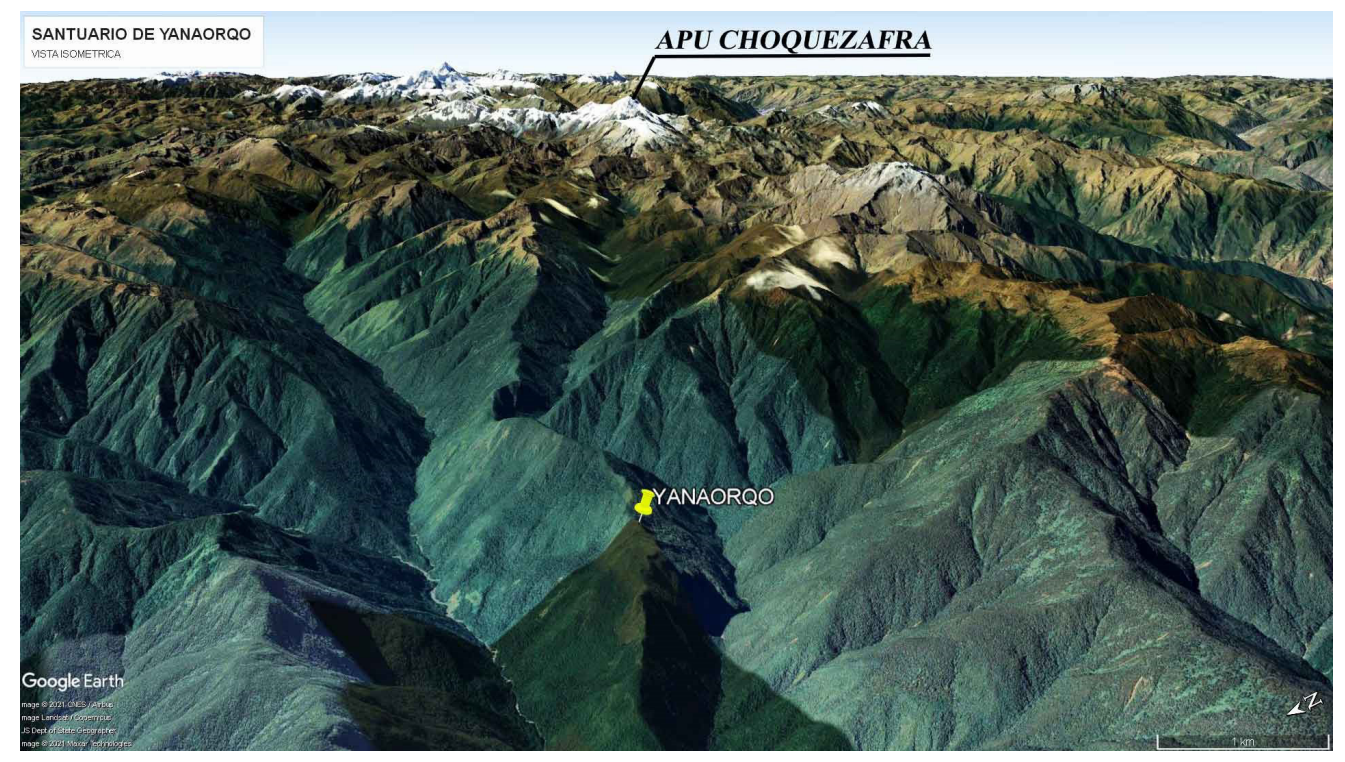

Figura 12. Proceso de excavación y medidas de mitigación para la conservación del santuario (2002).

\section{Peticiones y conversaciones de los Apus}

A los Apus no se les pregunta directamente, primero se les suplica pidiendo permiso, este proceso, aunque pareciera engorroso es de norma entre los sacerdotes andinos sensatos, mi lengua materna el quechua, así como entender la idiosincrasia de mis hermanos me han permitido percibir esta secuencia.

Cuando planifique uno de mis tantos viajes por Vilcabamba, mi madre quechua hablante me recomendó que primero debería hacer ver mi suerte en coca, inmediatamente recurrí a Don Nicasio Tito Huamán (sacerdote andino), para mirar mi destino en la coca invoco a los dioses y santos católicos, luego invoco el permiso a las deidades andinas en orden jerárquico y, a través de la interpretación en hojas de coca me manifestó que primero debíamos pedir permiso a los Apus, adquirimos una ofrenda bien surtida que luego lo ofrendamos en inmediaciones de Amaro Markawasi dentro del parque Arqueológico de Saqsayhuamam en la noche. Cuando se estaba quemando la ofrenda me interpretaba lo que los Apus decían:

Qhaway niñucha, apuschiskunan sumaqta chasquikushan kay haywarikuyta, paykunan niwashanku allintas ñannikipy purinky, mana manchakunaykipaq llama untuwan pichasun kurkuyquita, animuykitawan wahasun.

Mira niñito, nuestros Apus están recibiendo con agrado tu ofrenda, ellos me dicen que en tu camino estarás bien y para que no te asustes te limpiare con cebo de llama tu cuerpo y llamaremos tu animo (informe oral Nicasio Tito Huamán 2004) La traducción mía. 
Kay q'epichata aparikunki ñanninquipaq, mana imawanpas tupanaykipaq, picharikunanpaq.

Llévate este pequeño contenido para tu camino, para que no te encuentres con nada que este limpio y tranquilo (informe oral Nicasio Tito Huamán 2004) La traducción mía.

En las múltiples travesías por los diferentes caminos formales e informales el Qapaq Ñan, tuve oportunidad de conversar y libar con Nicanor Quispecusi, unas copas bien surtidas de cañazo, abundante chaccheo de coca, fumando cigarro y conversando en nuestro idioma nativo, en los breves descansos de largas jornadas de camino para ganarme su confianza. Nicanor es un arriero experimentado que conoce todas las rutas y caminos en la selva enmarañada y también hacia las montañas sagradas en la cordillera de Vilcabamba, el también acompaño a Santiago del Valle, en su recorrido en busca de Hatun Vilcabamba, el último refugio sagrado de los Inka por más de 15 años.

Cuando conversamos sobre las montañas en quechua entendi lo siguiente:

"Allinta purinanchispaq, Apunchiskunamanta mañakuna sonqonchis hujumantakama, sichus munanqa chayka, ñanninchispi rikuwasun mana llaqi kawananchispaq"

Si deseamos caminar bien sin novedad, tenemos que pedir a nuestros Apus desde lo más profundo de nuestro corazón, si desea nos vera y protegerá en nuestro camino para no tener penas.

“Chaypaqmi haywarina munasqhanta, chasquiwasun chayqa sumaqta qhosñirinq'a hanaq pachaman"

Para eso le debemos ofrendar lo que desea, si nos recibe el humo subirá en dirección al cielo. Q'asakunapi samariqti uyarinin, imainatas karumanta illapawan llipipispa qáparispa, rimanakunku, paykunapura, chaypin camachikunku maypis paranq'a asqhata otaq pisillata, mijuna kananpaq.

En las alturas de los cerros cuando descanso escucho la conversación entre ellos, se comunican a grandes distancias a través del estruendo del rayo brillando, ellos ordenan donde lloverá fuerte o despacio para que haya comida.

Hatun Apuq'a camachikun llipin hoqkunata, chullallatan qaparin.

El Apu mayor, ordena a los demás el habla una sola vez (Comunicación personal de Nicanor Quispecusi 2002) Traducción mía.

\section{La parentela y orden sagrado de los Apus}

Reinhard (2002) manifiesta que:

“...el culto a las montañas en los Andes, muestran al Apu Salkantay, con el nombre de (Orqo) macho en quechua, de sexo masculino, su esposa y mujer es el nevado de Huaca Huillca (Huacay Huillca, Waqaywillca conocida como 
la Verónica de 5,750 m.s.n.m.), cuyo nombre es China Salkantay (femenina en quechua). Es sugestivo de que ambos nombres se manejen para las dos cumbres del Salkantay: Urqo Salkantay como varón y China Salkantay como mujer. Debemos anotar que, al ser un Apu masculino, así como por su emplazamiento estratégico en vínculo estrecho con otras montañas que se ubican en su entorno como el Humantay (Tukarhuay 5,910 m s. n. m.), sea el de mayor poder" (Reinhard 2002, p. 21).

Según informe oral de Nicasio Tito Huamán (2011)

"Los apus de Salkantay y Ausangate son iguales (masintin) como hermanos, cada uno tiene su familia, la esposa del Apu Salkantay es la Verónica (Waqaywillca) sus hijos son el (Humantay ó Tukarhuay) hijo menor y (Yanantay ó Coyllur) hija menor, sus rebaños son los luichos, tarukas, vizcachas, poronq'oe etc, etc, cuando el Salkantay está disgustado por algo malo que hacen sus súbditos, empieza a rugir y botar nieve (desprendimientos de hielo de su cima), a mí se me señalo con la caída de un trueno sobre mi cabeza y mi iniciación fue en Singrina qocha (una de la lagunas formadas por el deshielo del Ausangate), por eso yo pertenezco como paq'o a la montaña de Ausangate."1

Esta información nos hacen ver el poder que emanan de las montañas luego como quechua hablantes, comprender la idiosincrasia local y basados en nuestras intensas caminatas por esta geografía agreste, donde se ubican estas divinidades, descubrimos que son una gran hermandad o cofradía, el principal y de primer orden es el Salkantay, que protege a Muchupicchu y Choquechurco, el Padreyoq y Coriwayrachina tienen bajo su tutela a Choquequirao, lo del Pumasillo es interesante, porque es una montaña con dos flancos por un lado tiene garras de roca y la más alta garras de hielo, esta tiene bajo su tutela otras montañas menores y valles del medio. El Panta es un pico remoto en el extremo occidental de la cordillera de Vilcabamba, se alza solo y se eleva por encima del bosque nuboso que lo rodea al borde de los Andes, bajo cuyo cuidado están los sitios de Ñusta Hispana y Rosaspata, los últimos bastiones inka.

Sobre Azul qocha no se tiene mucha información se sabe que es una montaña que otorga vida ya que de sus cumbres emana la vida convertida en agua fresca y tiene dominio en parte hacia la frontera del territorio de Hatun Vilcabamba. Finalmente está el Choquezafra que es el guardián de los valles interandinos de Toroq, Pati-

1. Tomado de "Cambio en el paisaje cultural de la montaña Salkantay y su impacto en las ideologías locales. El caso Soraypampa (Prov. de Anta, región del Cusco. Tesis presentada a la Unidad de Postgrado de la Facultad de Ciencias Sociales de la UNMSM Comunicación personal de Nicasio Ttito Huamán Comunero de Pampaq'amaradistrito de Ccatq’a provincia de Paucartambo (82 años) (Bolívar 2016). 
bamba, Chancavine, Pintobamba y lugar grande que se encuentran deshabitados, lo interesante de esta montaña que se emplazada en el extremo occidental en la cordillera del Vilcabamba, tiene como compañera y está emparentada al Chontawilca, una montaña femenina y que además es un Apu de menor rango.

\section{Planificación y ordenamiento territorial en Vilcabamba}

Las sociedades prehispánicas no estaban exentas sobre la comprensión de su territorio, ellos planificaban y ordenaban en base a las observaciones aprehendidas de sus ancestros, esta es una secuencia de acciones sociales, cuya premisa fundamental se inicia con el conocimiento del medio geográfico en etapas y obedece a un proceso temporal que se inicia desde el Horizonte Temprano, se acentúa en el Horizonte Medio y consolida en el Horizonte Tardío, aun hoy continuamos con esta tarea. De igual modo una de los primeros escollos a pasar, es el de la adaptación al medio ambiente y geográfico de los actores sociales, una vez logrado este se tienen que identificar los puntos de orientación y señales en el paisaje, cuyo papel recae en los cerros y montañas más visibles atribuyéndoles poderes sobrenaturales como parte de la construcción cognitiva, para luego convertirlas en sus deidades, que los protegen en sus territorios

La planificación y ordenamiento en el territorio siempre ha sido una construcción y operación social ineludible que representa un estilo de desarrollo evidente de las sociedades que la comienzan, en este caso nuestras sociedades prehispánicas tienen su impronta en la utilización de la geografía su paisaje y su transformación social basada en la observación y ubicación de las montañas deidades y Apus. Esta se va formando desde épocas muy tempranas y continuara inexorablemente hacia el futuro, mediante las diligencias que los actores sociales y sus principales practican sobre el medio físico con interacciones que se dan a través de canales de relación que proporcionan funcionabilidad al sistema y que recae en la obtención de recursos energéticos y económicos.

La consolidación del enclave es en función del medio geográfico y la implementación de infraestructura en este caso para Vilcabamba la Grande, es el recinto de culto o santuario en Yanaorqo, que funciona para satisfacer las demandas de la montaña echa deidad como el Choquezafra.

Luego de la destrucción de la capital inka el Cusco, por lo españoles, Manco Inka y sus huestes con el fin de recuperar el esplendor de su organización, se internan en la espesura de la floresta y cordillera del Vilcabamba, que ofrecía un escenario adecuado para la continuidad de su ideología, organización y emplazamiento del otro Cusco, que debía tener poder prestigio y vigencia.

El concepto Cusco fue propuesto por Apaza y Bolívar (2016) y sostienen los siguiente: 
“... es importante establecer que los otros Cusco, no son una copia espacial o arquitectónica del Cusco principal, más bien es una construcción bajo el concepto Cusco, armonizándose con la geomorfología y medio ambiente de la zona, lo que implica que la modificación (construcción) de su espacio, mental o geográfico se sustenta en que estos estaban entendidos bajo los criterios de lo que significaba este Otro Cusco, núcleo del sistema de organización y manejo de este espacio territorial, esto se repetiría de la misma manera en todo el Tawantinsuyo". En: El Otro Cusco: Choquequirao (Apaza y Bolívar 2016, p. 165-196).

Por lo que el Cusco como concepto fue toda una institución simbolizada, esta tenía que ser recreada al interior de esta geografía, por lo que se traslada toda esta institución a este espacio, por ejemplo, la pacarina principal o lugar de origen el Huancaure, fue reemplazado por el Choquezafra, que no solo cumplió este rol, sino que también fue el guardián y protector de Hatun Vilcabamba (la perdida) último refugio de los inka, tuvo su Coricancha que también fue recreado ya no con el esplendor que esta tenía en el Cusco, la capital sino que fue una edificación consistente en una estructura religiosa con 8 hornacinas, 4 al fondo, 2 a cada costado y acompañando al acceso otras 2, cuyo acabado estaba complementado con un revoque de arcilla y pintado, emplazado en la cima del cerro Yanaorqo, la cual excavamos el 2002.

Salkantay. Otorga la vida a través de las aguas que emanan de ella es considerada un oráculo de la más alta jerarquía entre las montañas altas en la codillera de Vilcabamba y guardián sagrado de Machupicchu y alrededores, este fue muy adorado durante la época prehispánica y aun continua en la actualidad, Bolívar y Dueñas 2016) manifiestan los siguiente: "Expresado en el imaginario religioso popular del siglo XVI, el Apu Salkantay es catalogado como un "señor protector», que resguarda a los pueblos de Limatambo, Mollepata, Machupicchu y Choquequirao emplazados en la cordillera del Vilcabamba, manteniéndose «majestuoso y señorial»" (Bolívar y Dueñas 2016, p. 245)

Padreyoq. Con 5771 m s. n. m., es el Apu principal, guardián de Choquequirao conjuntamente que el Qoriwayrachina, Choquetakarpo, Pumasillo y Panta, además es el que abastece de agua a través de canales prehispánicos como el de Suyrucoqha, y Qoriwayrachina, también alimenta el riachuelo Ch'unchumayu, fruto el deshielo de su cumbre.

El Macizo del Panta. 18L 712281E 8539825S Según Carlotto y otros (1999) se emplaza en el cuadrángulo Pacaypata extendiéndose con el de Machupicchu a través de diversos pequeños cuerpos, nombrados como almacenamiento de Cayara. Continúan describiendo el cuerpo céntrico, que se vislumbra estirado con dirección Noreste-Suroeste, aquí se encuentra con el cerro Chucuito, que: 

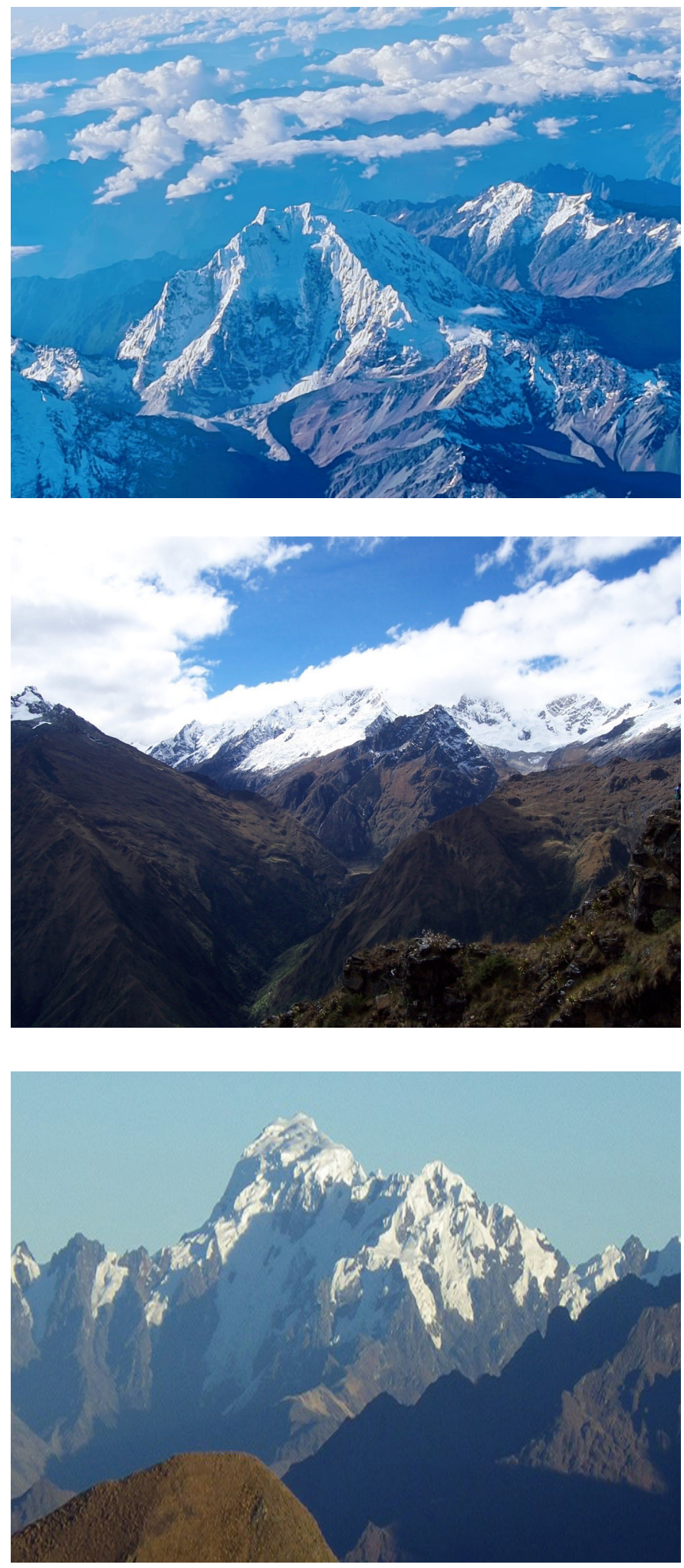

Figura 17. La montaña sagrada del Salkantay enclavada en la cordillera. Foto Jorge Luis Delgado (2021) tomado de Facebook 12/07/2021.

Figura 18. El Padreyoq y Qoriwayrachina, macizos graníticos por encima del valle del río Apurímac guardianes de Choquequirao, vistas por detrás en camino al poblado de Yanama (2012).

Figura 19. El macizo del Panta y su topografía imponente Foto Santiago del Valle (2013). 
"Incluye rocas metamórficas de la Formación Quillabamba del (Siluro-devoniano) que a su vez es constituido por rocas del Pumasillo perteneciente al (Permo-triásico). En el norte, en el cerro Tunisca, se tiene otro afloramiento que se halla seccionando rocas de la Formación Quillabamba y en empalme fallido con rocas del Grupo Copacabana. Al Sur se tienen dos pequeños cuerpos prolongados y controlados por fallas, intruyendo a rocas de la Formación Quillabamba y del Cambriano, que están afectadas por rocas intrusivas permo-triásicas del Pumasillo. También se tiene afloramientos de pequeñas extensiones denominadas (Chupán y Choquetacarpo) que se cuelgan dentro del intrusivo permo-triásico". (Carlotto et al 1999, p. 89-90).

El Pumasillo. (Garras de puma) 18L 719343E 8532969S 5.950 m.s.n.m., área dominada por Pumas, hijos y guardianes de la montaña, es un Apu con dos flancos por un lado tiene garras de roca y por la otra garra de hielo, es alta, tiene bajo su tutela otras montañas menores y al otro Cusco Choquequirao. Esta montaña está en franco proceso de deshielo y luce calato sin vestimenta, según creencia de pobladores de la zona.

De nuevo Carlotto y otros (1999) manifiestan:

“...que este macizo de forma rectangular y de dirección este-oeste ocupa grandes extensiones de la parte septentrional del cuadrángulo de Machupicchu y se prolonga hacia el cuadrángulo vecino de Pacaypata citan a Cárdenas y otros (1997) que a su vez sostiene que este cuerpo intrusivo en la zona de estudio tiene una superficie de $536 \mathrm{~km} 2$. En su borde norte intruye a rocas del Grupo San José. En su borde este y sur corta rocas del Cambriano, mientras que hacia su borde oeste corta rocas del Paleozoico inferior e intrusivos devonianos" (Carlotto y otros 1999, p.106).

Pumasillo. (Garra de Hielo) 18L 736559E 8539504S, a diferencia de la otra esta es más benévola, porque controla el clima y otorga vida a través de agua que sale de su cumbre, es guardián y protege igual que su masintin a Choquequirao.

Azulrithy-azulcocha. 18L 704356E 8537390S, a 5269 m s. n. m., es una montaña no muy conocida en la literatura, se encuentra en el medio de dos Apus, el Panta y Choquezafra, juega un rol importante en la idiosincrasia y culto de poblados emplazados en los valles que domina esta montaña, además porque desde su cima emana agua que da vida a los animales, hace florecer la agricultura, es un Apu local que conversa y colabora junto con a otros Apus y protege a sus hijos.

Choquezafra. 18L 693398E $8537627 \mathrm{~S}$ altitud $5184 \mathrm{~m}$. Es la montaña emplazada hacia el occidente de la cordillera del Vilcabamba, se localiza en un área deshabitada es el "Apu Principal" o montaña sagrada de primer orden de la zona, tiene una silueta mágica de crestas rocosas en su cumbre que irradia temor a sus ocasionales 
visitantes. Desde esta posesión privilegiada se puede disfrutar de una visualización del paisaje que brindan otros nevados como el Panta y Azulcocha,

La cresta se compone de rocas graníticas en descomposición producto del deshielo, de igual modo se puede distinguir grietas en proceso de meteorización, los cuales forman un río de piedras blancas llamadas Yuracmayu (rio blanco). Esta montaña es el protector del ultimo Cusco Inka construido en el cerro Yanaorqo.

Chontawilca. Es una montaña alargada y coligada al Choquezafra como la acompañante por considerarse un Apu femenino y emplazado en el punto 18L $699666 \mathrm{y}$ E8527468 S altitud $4586 \mathrm{~m} \mathrm{s.} \mathrm{n.} \mathrm{m}$.

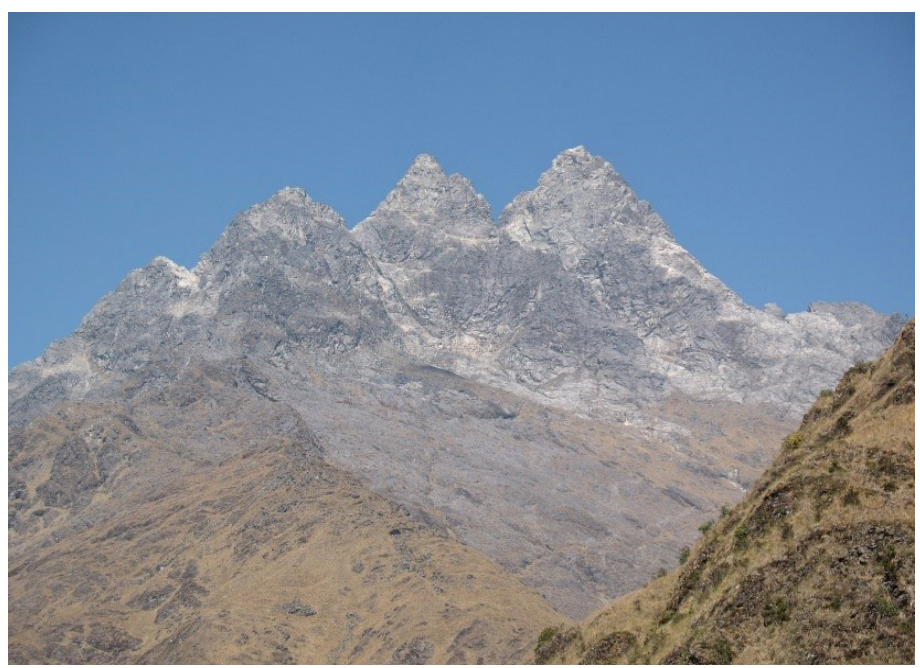

Figura 20. Pumasillo de lejos mostrando sus garras Cortesia Santiago del Valle (2008)

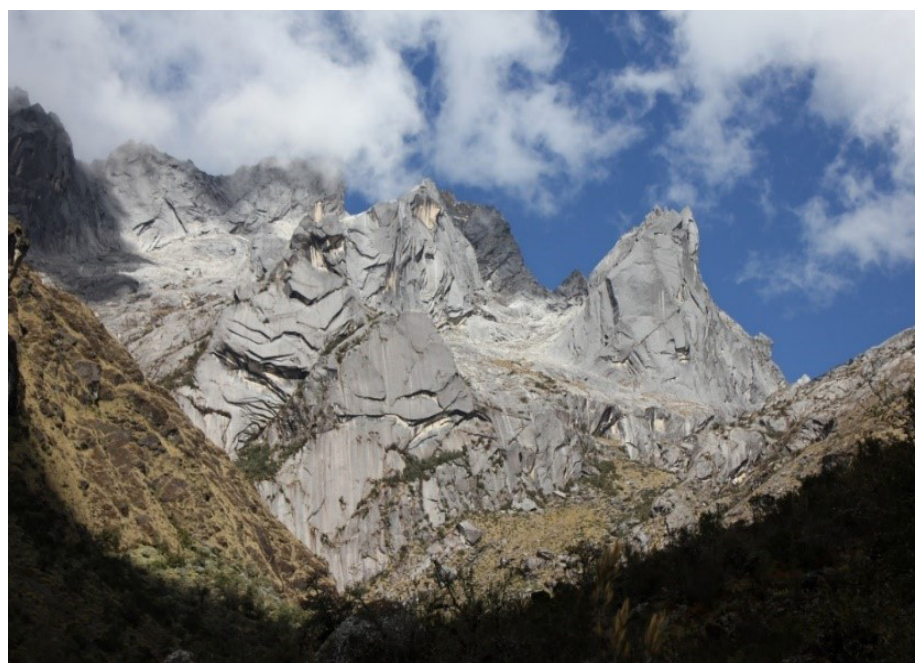

Figura 21. Pumasillo compuesto de monzogranitos, según Carlotto (1999) "Tiene textura granular subhedral de grano grueso, con presencia de microclina pertítica anhedral a subhedral". 

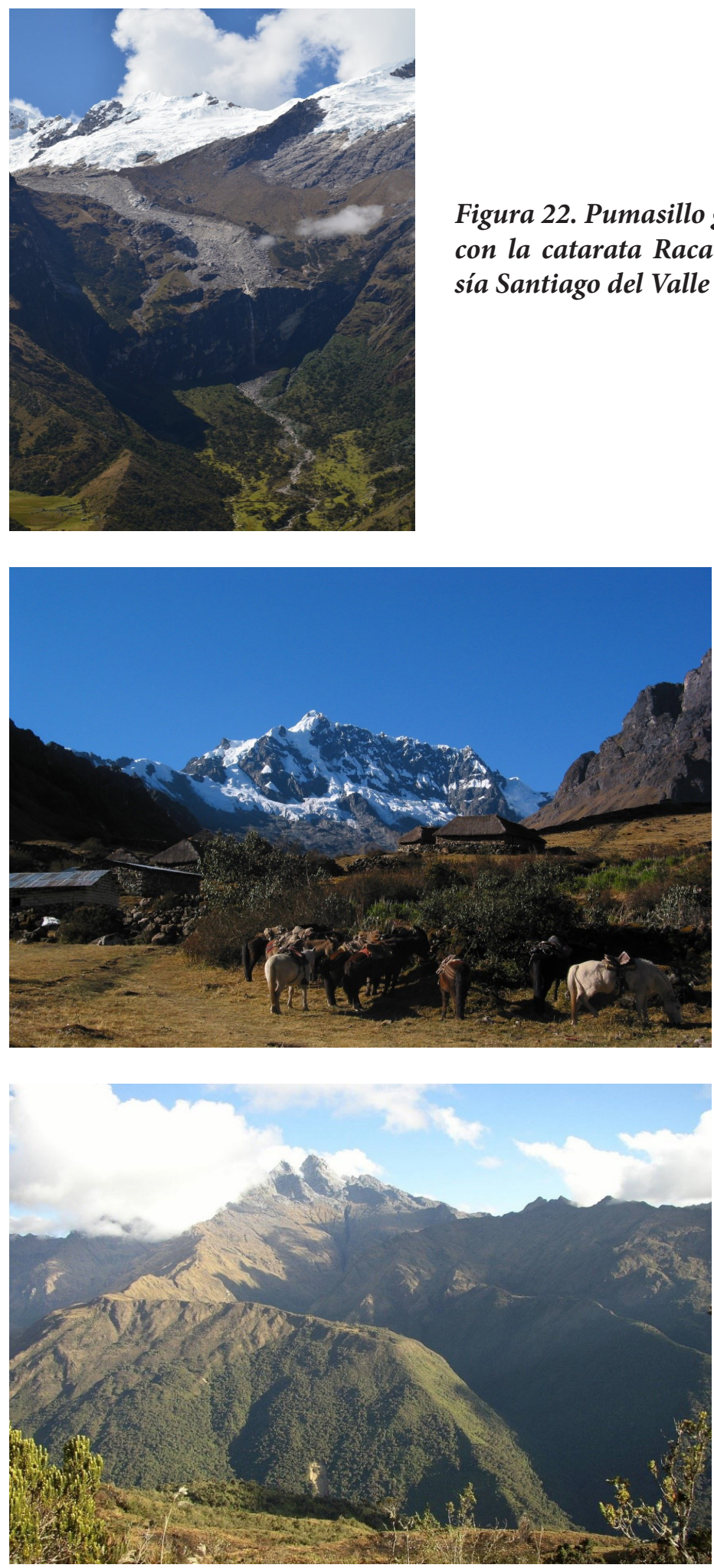

Figura 22. Pumasillo garra de hielo con la catarata Racachaca: Cortesía Santiago del Valle (2015).

Figura 23. Azulrithy- azulcocha desde Porcay, foto cortesía Santiago del Valle (2013).

Figura 24. Los Apus Choquezafra y Chontawilqa (Macho y Hembra), son encargados de cuidar el territorio donde está emplazado Hatun Vilcabamba, con su centro ceremonial en Yanaorqo, Foto cortesía Santiago del Valle (2013). 


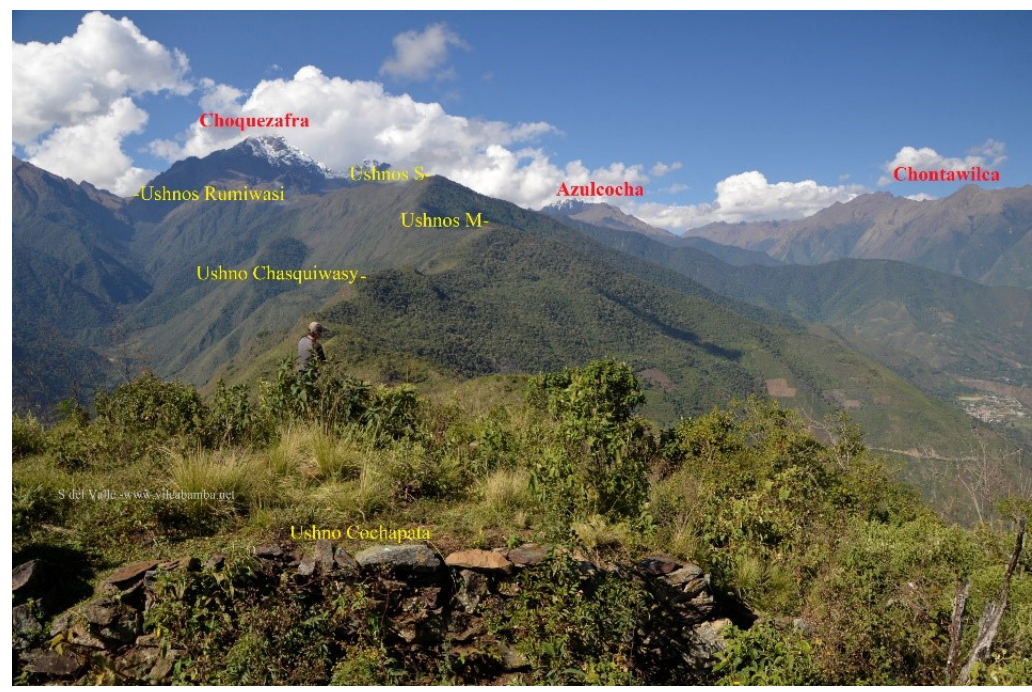

Figura 25. El Choquezafra, Azulcocha $y$ Chontawillca con los Ushnus para su adoración desde otros angulo. Cortesia Santiago del Valle (2008).

\section{APROXIMACIONES}

El poder de las montañas se calcula por el espacio geográfico que domina el mismo que está demarcado por la visualización que se tiene de ellas, por ejemplo, las montañas del Salkantay y Ausangate aparte de ser masintin, (iguales) pueden ser divisadas desde grandes distancias.

Estas siempre han asumido un papel significativo en el pensamiento prehispánico y actual, puesto que son imponentes enclavadas en esta geografía sacra, además están circunscritas dentro un paisaje cultural imaginado desde épocas inmemoriales, por sociedades prehispánicas. Según Bolívar (2016) conforman una parentela sagrada, otorgan la vida por medio del líquido elemento que proviene de sus cimas (nieves perpetuas) de igual modo detentan poderes sobrenaturales.

Condicionado a las antiguas poblaciones andinas a adorarlos, luego para atenderlos y rendirles pleitesía edificaron estructuras ceremoniales y/o administrativas entre ellas Machupicchu, Choquequirao, Nusta Hispana, Rosaspata, Espiritupampa (otros Cusco) y enclaves ceremoniales como Choqhechurco y Yanaorqo, asociadas a caminos Prehispánicos algunos de ellos de peregrinación.

$\mathrm{Su}$ visibilidad a grandes distancias fue esencia de gran fervor en época Inka, aún continua en la actualidad, definidos en función del espacio habitado, sacralizando paisajes privilegiados, esencialmente si consideramos la energía utilizada en el número importante de infraestructura construida en cerros de la cordillera del Vilcabamba.

Estas poblaciones prehispánicas, contemplaban a sus montañas como la plasmación de sus dioses, por esto siempre les rindieron culto y tributo a través de ofrecimientos y rogativas, sin ascenderlo por temor a ser castigados, este hecho hace 
que se pueda considerárseles también como oráculos consultados en los santuarios, las montañas contestaban a los sacerdotes que transmitían los mensajes a los fieles y viajeros, estos sacerdotes dedicados al culto, y mantenimiento de estructuras ceremoniales vivían en ellas, (Choquechurco y Yanaorqo) estos adquirían poderes sobrenaturales en el lapso de los ritos ceremoniales en los que recibían mensajes.

Finalmente, los adoratorios o santuarios son estructuras materiales que quedaban emparentados con las montañas sagradas, cuyos elementos como el ambiente la fertilidad de los campos y los fenómenos meteorológicos estaban ligados a estas. Complementando el concepto Cusco la cima del cerro también se convirtió en un espacio sagrado, en dirección al Choquezafra, en la que se designaron espacios sagrados para colocar el Punchao, y continuar con la religiosidad inka, manteniendo vigente la ideología y sus instituciones.

\section{REFERENCIAS BIBLIOGRÁFICAS}

Apaza, J. y Wilber, B. (2016). El Otro Cusco: Choquequirao. En: Arqueología y Sociedad $N^{\circ} 31$ del Museo de Arqueología y Antropología de la UNMSM. pp. 65-196

Bolívar, W., Apaza, J., Lagos, G., Castro, J., y Soto, M. (2019) Caminos hacia los otros Cuscos: Choquequirao. En: Arqueología Peruana del COARPE. Revista del Colegio Profesional de Arqueólogos del Perú Nº 2 Pág. 63-96

Bolívar, W. (2015). Cambio en el paisaje cultural de la montaña Salkantay y su impacto en las ideologías locales. El caso Soraypampa (Provincia de Anta, región del Cusco). Tesis presentada a la Unidad de Postgrado de la Facultad de Ciencias Sociales de la UNMSM, para optar el grado de magíster. Pág. 176-187

Bolivar, W. y Yony, D. (2013). La montaña sagrada de Salkantay: su paisaje, poder y ancestros. En: Arqueología y Sociedad 26.

Bolívar Yapura, Wilber. (2002). Informe Final del Proyecto de Exploración e Investigación Arqueológica en Vilcabamba la Grande. Expedición Juan de Betanzos. Presentado al Instituto Nacional de Cultura-Cusco.

Bunge, M. (1981). La Investigación Científica. Su Estrategia y su Filosofía, México, Editorial Ariel, octava edición.

Criado Boado, F. (1999). Del terreno al espacio: planteamientos y perspectivas para la Arqueología del Paisaje. Capa 6. Criterios y Convenciones en Arqueología del Paisaje. Grupo de Investigación en arqueologia del paisaje de la Universidad Santiago de Campostela.

Cárdenas, J.; Carlotto, V.; Romero, D.; Jaimes, F. \& Valdivia, W. (1997). Geología de los Cuadrángulos de Chuanquiri y Pacaypata. Hojas 26-p y 27 -p. Bol. 69, Serie A: Carta Geológica Nacional, INGEMMET, 208 p. Lima-Perú. 
Carlotto, V., Cárdenas, J., Romero, D. Valdivia, W. Daniel Tintaya. (1999). Geología de los cuadrángulos de Quillabamba y Machupicchu. Boletín No 127 Serie A: Carta Geológica Nacional. Sector Energía y Minas Instituto Geológico Minero y Metalúrgico (pp. 89-90).

Del Valle, C. (2016). Vilcabamba. El refugio Sagrado de los Incas. Ediciones del Viento, impreso en Kadmos, España.

Jiménez, B., \& Tejada, J. (2004). Procesos y Métodos de Investigación. En J. Tejada , V. Giménez , F. Gan, M. Fandos, J. Jiménez, \& Á. Gonzáles, Formacioin de formadores. Escenario Institucional. (Vol. 2). España: Thomson Editores Spain.

Jhonson, M. (2008). Arqueologia del Paisaje. Arqueología Conceptos Clave. Colin Renfrew y Paul Bahn (Eds).

Murra, J. (1975). El control vertical de un máximo de pisos ecológicos en la economía de las sociedades andinas. En Formaciones Económicas y Políticas del Mundo Andino (pp. 59-115). Lima: IEP

Reinhard, Johan. (2002). Machupicchu. El centro sagrado. Instituto Machu Picchu. Cusco, Cimagraf .Pág. 21, 35.

Soto Huanco, M. (2016). Identificación y Registro del Sistema Vial Andino en los Ocho Tramos Machupicchu Integral-Vilcabamba, Provincia de la Convención. Revista Patrimonio. Qhapaq Ñan Caminos de Diversidad e Integración. Dirección Desconcentrada de Cultura de Cusco.

\section{SOBRE EL AUTOR}

\section{Wilber Bolívar Yapura}

Arqueólogo egresado de la Universidad Nacional de San Antonio Abad del Cusco, Magíster en Gestión del Patrimonio Cultural por la Universidad Nacional Mayor de San Marcos, Candidato a Doctor en Ciencias Sociales, Gestión Pública y Desarrollo Territorial por la Universidad Nacional del Altiplano-Puno. Es docente en la Escuela Profesional de Arqueología UNSAAC. Miembro de Instituciones como del Centro Internacional de Monumentos y Sitios (ICOMOS), ex-Decano Nacional del Colegio Profesional de Arqueólogos del Perú. Ha publicado varios artículos en revistas indexadas con temática sobre montañas sagradas, caminos prehispánicos a los otros Cuscos, la muerte, Amazonía, arte rupestre, Centro Histórico del Cusco, etc.

Codirector y coeditor de las Revistas de Arqueología Peruana del COARPE, Números 1 y 2. Ha brindado conferencias a nivel nacional en ciudades como Lima, Ayacucho, Huaraz, Cusco y Puno, y en países como México: ciudades de Pachuca de Soto Hidalgo y México DF., y en Bolivia: ciudades del Alto y La Paz. 


\title{
Semántica de la imagen bilobulada de la cabeza en el antiguo hombre de la costa central andina de Chancay-Ancón (Perú). ¿Una relación con la Diosa lunar - Diosa del mar?
}

Semantic of the bilobulated image of the head in the ancient man of the central andean coast of Chancay-Ancón (Perú). A relationship with the lunar goddess- goddess of the sea?

\author{
Zoila Rosaura Yépez Vásquez \\ https://orcid.org/0000-0001-6387-8425 \\ Universidad Autónoma del Estado de México \\ zryepezv@uaemex.mx
}

\section{RESUMEN}

Las culturas de Chancay-Ancón (1200 a 1400 años d. C.), llevaron a cabo la práctica cultural de modelar la cabeza. Ambos grupos, evidencian el tipo de modelado cefálico fronto occipital oblicuo y otros en el tipo erecto, con un rasgo distintivo cefálico al portar «una forma simbólica bilobulada de la cabeza», la cual está representada en el arte cerámico antropomorfo desde el Horizonte Medio (800-1100 años d. C.) hasta el Horizonte Tardío y la Conquista Inca (1200 a 1532 años d. C.). Del mismo modo esta «forma cefálica de modelar» está representada con la diosa del Mar (o diosa Tierra, o diosa Lunar). Por tanto, esta dimensión del pensamiento andino, alude a qué la cabeza con una imagen bilobulada entre los antiguos costeños, estaría 
asociada con los cultos lunares, o bien podría existir una relación de identidad o de fertilidad con la imagen corporal de la diosa Lunar, diosa Tierra o diosa del Mar. Al respecto se plantea, ¿Qué relación de reciprocidad podría existir entre «la imagen bilobulada de la cabeza» del poblador antiguo de Chancay-Ancón, con la «imagen bilobulada de la cabeza de la diosa del Mar-diosa Lunar o diosa Tierra?

Palabras clave: semántica, imagen, metáfora, cabeza bilobulada, símbolo, Diosa lunar

\section{ABSTRACT}

The Chancay-Ancón cultures (1200-1400 years AD), carried out the cultural practice of cephalic modeling, both groups show the oblique fronto occipital type of modeling and others in the erect type, with a distinctive cephalic trait, "a bilobed symbolic head shape", which is represented in anthropomorphic ceramic art from the Middle Horizon (800-1100 AD) to the Late Horizon and the Inca conquest (1200$1532 \mathrm{AD}$ ). In the same way, this "form of cephalic modeling" is represented by the goddess of the Sea (or Earth goddess, or Moon goddess). Therefore, this dimension of Andean thought, would be alluding to what the head with a bilobed image among the ancient coastal people, would be associated with the lunar cults, or there could be a relationship of identity or fertility with the body image of the Lunar goddess, goddess Earth or goddess of the Sea. In this regard, What reciprocity relationship could exist between the "bilobed image of the head" of the ancient Chancay-Ancón inhabitant, with the "bilobed image of the head of the Sea goddess-Lunar goddess or Earth goddess?

Keywords: semantics, image, metaphor, bilobed head, symbol, moon goddess.

ReCiBIDO: 20/09/2021 - ACEPTADO: 08/10/2021 - PUBLICADO: 25/11/2021

\section{INTRODUCCIÓN}

El hombre desde la antigüedad tuvo la idea de modificar y decorar su cuerpo a través de una diversidad de formas ${ }^{1} \mathrm{y}$ colores que se establecieron y se instauran como procesos de «significación y comunicación social»»; y, entre las prácticas corporales de más arraigo cultural y que ha llamado la atención fue la práctica étnico-cultural de modelar la cabecita entre los bebés recién nacidos en los diferentes pueblos del centro andino. El interés de aproximarse a conocer las dimensiones de lo imagi-

1. El término de "forma" retomo de Pedro Weiss (1962) quien sostenía, que a las modificaciones culturales de la cabeza, habría que identificarlas como «formas» de deformar el cráneo. Desde nuestro punto de vista muy occidentalizado las nombramos como "deformaciones craneanas"; sin embargo para el antiguo poblador andino modificar culturalmente una parte de su cuerpo, no significó deformarlo, sino más bien, «darle una determina- 
nario, de ese conjunto de imágenes plasmadas en el cuerpo y su red de relaciones culturales, constituye el capital simbólico del pensamiento humano. Este imaginario, es la intersección central que permitirá esclarecer en este caso, el problema de la investigación relativo a la significación, al símbolo y al pensamiento mitopoético del antiguo hombre andino de la costa y su práctica cultural de modificar la cabeza con una imagen bilobulada (figura 1a y 2 y 3 en anexos). Una semántica ${ }^{3}$ de las imágenes ${ }^{4}$, que le dio una configuración metafórica ${ }^{5}$ a su cuerpo, "lienzo de redes simbólicas" entrelazadas con su mundo cosmogónico; y, que de acuerdo a Wartofsky (1996, pp. 21-22), si nos preguntamos por el origen de la cosas de cómo y por qué existen, hablaremos de «cosmogonía»; disciplina que se ocupa de los problemas referentes a las caracterizaciones del origen de las cosas en función de algún principio, fundamento, o causa, o propósito. En este sentido, el tema es amplio; por lo que, nos centraremos en analizar la relación de la cabeza bilobulada del poblador antiguo de Chancay y Ancón; con su probable relación de identifidad-fertilidad con la imagen corporal de la diosa Lunar y/o del Mar.

La imagen corporal del antiguo hombre de Chancay-Ancón, con especial singularidad, de la "forma simbólica bilobulada de la cabeza", lleva hablar del cuerpo, de un cuerpo que habla a través de signos simbólicos, por tanto es cuerpo semiótico,

da forma simbólica a su cabeza» con fines y motivos de acuerdo a su complejo ideológico y sistema de creencias bajo el cual militó su vida cotidiana, como también su vida económica religiosa y política.

2. Retomo estos conceptos desde una perspectiva semiótica de Umberto Eco (2010) quien sostiene que un proyecto de semiótica general constituye analizarlo desde sus procesos de significación (códigos) y de comunicación (signos, símbolos). Trasladando estos términos dentro del estudio arqueológico y antropológico de las prácticas culturales de modificar el cuerpo, implica que, los procesos de comunicación nos llevará a indagar acerca de esos elementos sígnicos (signos) que el hombre ha utilizado para darles una connotación simbólica. La significación, se referirá a los códigos sociales establecidos por los etnos para reglamentar una determinada práctica social o cultural que ha de regir en la agrupación o sociedad en general, como debió ser la práctica cultural de moldear la cabecita de los bebés recién nacidos.

3. El término semántico tiene su origen en el griego semaino, y denota "significar", al mismo tiempo comparten la raíz sêma, "signo". Semaino en un principio era el adjetivo "sentido". Por ejemplo, cuando se da un cambio semántico es también un cambio de sentido, por lo que "el valor semántico de una palabra es su sentido" (Guiraud, 1986).

4. Parra (2014) indica que: "la imagen, es un compuesto de realidad sensible y representación abstracta que garantiza la adopción funcional del entorno, que guarda la articulación espacio-temporal". Una definición similar expresó Saussure cuando escribió respecto al signo: "Llamamos signo a la combinación del concepto y de la imagen acústica" (Saussure 1945, p. 129). De acuerdo a Parra, «Saussure redefinió luego "el concepto y la imagen acústica" como significante y significado, con lo cual ampliaba el espectro de percepción de lo sígnico hacia un nivel más general, que puede abarcar otros sistemas de integración funcional, como la imagen, por ejemplo, que le permitió a Barthes, posteriormente, elaborar su reflexión sobre la retórica de lo visual» (Parra Valencia 2014, p. 81).

5. El sustantivo «"metáfora" es la expresión más característica de la retórica. Existe un modo racional de expresar el mundo, cuya piedra angular es el concepto; y existe una forma retórica de expresión, basada en la metáfora. Estas formas expresivas no son ajenas al problema del conocimiento, por lo que podemos incluso decir que la metáfora es el modo expresivo por excelencia del mecanismo de conocimiento retórico» (Pujante 2003, p. 206). “...La metáfora, como otros tropos y figuras, construye una visión del mundo y determina su pensabilidad" (Vico, apud Pujante, 2003, p. 210). (tomado de Sal Paz, 2009). 
cargado de comunicación (signos) y significación (códigos). De ahí que, Katya Mandoki (2008, p. 14) alude:

El cuerpo como agente discursivo no es solamente retórico. En los primeros momentos de nuestra vida es el cuerpo el medio de comunicación más básico. El lenguaje gestual o corporal se expresa, en primera instancia, en la función expresiva según el modelo de Jakobson. El acto de sonreir, llorar, besar, abrazar, golpear y hacer contacto con la mirada son actos en que se ejerce la función expresiva del lenguaje corporal ${ }^{6}$. Así, la función fática se establece al dar la mano, saludar o despedirse agitándola. La función metalingüística ocurre no sólo en el lenguaje de los sordomudos sino también, aunque de manera más elemental, en los gestos paralelos al habla verbal que realizamos para enfatizar lo que estamos diciendo. La función referenciall se establece en los denominados deícticos literales, como apuntar con el dedo para señalar a algo, a alguien o hacia algún lugar. La función poética corporal esta, desde luego, de manera directa en la danza como presentación, y en la pintura figurativa y la fotografía como representación. Por último, es la función conativa la que se vincula con la retórica del cuerpo.

La cita de Mandoki (ídem) lleva a considerar un apartado de Michel Bernard (1994, p. 200) cuando hace alusión al principio de la horda primitiva que hace del cuerpo, el cuerpo de la tierra y lo territorializa [...]. Así, en dicho y este contexto, imagino el fundamento (causas) de los antiguos etnos andinos, al establecer códigos sociales como la génesis para reglamentar la práctica cultural de modelar la cabeza; distinguiendo una parte metafórica del cuerpo, como un símbolo del cosmos, de la tierra y de los dioses. Modificar el cuerpo para darle una determinada «forma simbólica bilobulda de la cabeza» hace de ésta, su cuerpo relacionado con el cosmos, estableciendo seguramente, relaciones de «complementariedad y reciprocidad en la ecosofía andina» (Estermann, 2013).

Así, la imagen corporal del antiguo hombre costeño andino de Chancay-Ancón, con la «forma simbólica bilobulada de la cabeza» y además representada en la ce-

6. Pierre Guiraud (1986, p. 7) aduce "hablamos con nuestro cuerpo y nuestro cuerpo habla de varias maneras y a varios niveles". Estimo que el cuerpo habla lingüísticamente (oralmente, por escrito también lo hace) y también el cuerpo habla semióticamente, es decir a través de signos, símbolos, íconos. Afirmaría que las prácticas culturales de moldear o modelar la cabeza, es el cuerpo que habla a partir de signos simbólicos. Por ejemplo, la «la forma simbólica bilobulada de la cabeza» del antiguo hombre de Chancay -Ancón, está expresando un signo simbólico desde el contexto de su cultura, de esa complejidad ideológica de sus creencias a partir de su modelo cosmogónico, en donde se originó los motivos y fines de dichas prácticas corporales.

7. "La función referencial opera igualmente en la retórica corporal, pues siempre se trata de discursos que se refieren a alguien o a algo, a sea real o imaginario. Entre todas estas funciones, la dominante en última instancia es siempre la conativa, por su naturaleza propiamente persuasiva, y la subdominante es estética, por su capacidad de conmover la sensibilidad del destinatario (pathos)" (Mandoki en Alarcón, 2013). Definida la retórica del cuerpo como híbrida de funciones, cuya dominante es conativa y la subdominante estética [...] (Mandoki, op. cit.: 15-16). 